AROUEOLOGÍA Y SOCIEDAD

№ 25 , 2012: $57-88$

1SSN: 0254-8062

RECIBIDO: JUNIO DE 2012

ACEPTADO: OCTUBRE DE 2012

\title{
LOS PATIOS CON ESTRUCTURAS ESCALONADAS DE HUACA PUCLLANA: CARACTERIZACIÓNY FUNCIÓN DE UNA AROUITECTURA CEREMONIAL LIMA
}

\author{
ISABEL FLORES ESPINOZA

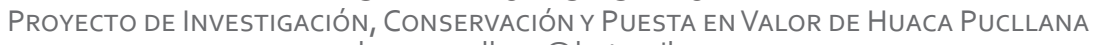 \\ huacapucllana@hotmail.com \\ Pedro Vargas Nalvarte \\ Proyecto de InVestigación, Conservación y Puesta en Valor de Huaca Pucllana \\ lanzong@hotmail.com \\ José CCENCHO HuAMANí

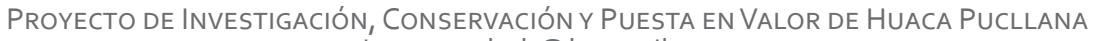 \\ joseccenchoh@hotmail.com \\ HERNÁN SiLVERA LA TORRE \\ PRoyecto de INVESTIGACIÓN, CONSERVACIÓN Y PUESTA EN VALOR DE HUACA PUCLLANA \\ herman_452@hotmail.com
}

\section{RESUMEN}

Los patios con estructuras escalonadas constituyen la unidad arquitectónica más recurrente en Huaca Pucllana, en este artículo se aborda una descripción detallada de éstas, así como, una caracterización general y una propuesta acerca de su función e importancia en el mundo ritual de la cultura Lima. La evidencia de Pucllana muestra características peculiares en cuanto a conservación y secuencia arquitectónica que permite realizar una propuesta global que abarque funcionalidad y cronología. Asimismo, se da revisión a la bibliografía existente acerca de este tema para así sustentar una propuesta que sirva para otros sitios Lima y ayude a caracterizar la arquitectura monumental del Periodo Intermedio Temprano de la costa central.

PalabRas Clave: Cultura Lima, Huaca Pucllana, patio con estructura escalonada, arquitectura, cronología, funcionalidad.

\section{Abstract}

The courts with staggered structures constitute the architectural unit more numerous in Huaca Pucllana, in this article a detailed description is approached of these as well as a general characterization and an 
offer brings Lima over of his function and importance in the ritual world of the culture. Pucllana's evidence shows peculiar characteristics as for conservation and sequences architectural that allows realizing a global offer that includes functionality and chronology. Likewise, one gives review to the existing bibliography brings over of this topic this way to sustain an offer that serves for other sites Lima and helps to characterize the monumental architecture of the Early Intermediate of the central coast.

KeYwords: Lima culture, Huaca Pucllana, court with staggered estructure, architecture, chronology, funionality

\section{Generalidades}

Huaca Pucllana es un sitio arqueológico, considerado como un centro ceremonial de la cultura Lima, construido aproximadamente entre los años 300 y 700 d.C. (Kroeber 1954: 91; Patterson 1966:113; Stumer 1954; Flores 1981, 2005; Flores et al. 2012). Ubicado en el valle bajo del río Rímac, en la costa central del Perú, es estudiado por Isabel Flores y un equipo multidisciplinario desde 1981 a la fecha, estos trabajos han logrado mostrar evidencias de la ocupación monumental Lima, la funeraria Wari y la última reocupación tardía que parece prolongarse desde tiempos inmediatos a Wari hasta tiempos coloniales tempranos (Flores 2005). El sitio está compuesto, en la actualidad, por una pirámide alargada de $300 \mathrm{~m}$ de largo, $80 \mathrm{~m}$ de ancho y $25 \mathrm{~m}$ de alto con construcciones adyacentes en la parte baja, ocupando seis hectáreas. La destrucción ocasionada por la habilitación urbana destruyó otras pirámides de menor tamaño y plataformas bajas colindantes a la pirámide que aún sobrevive. Los trabajos se realizan en el marco de un convenio de cooperación interinstitucional entre el Ministerio de Cultura y la Municipalidad de Miraflores.

Hasta el momento se ha excavado el 65\% de la superficie de la zona arqueológica, exponiéndose mucha arquitectura; la unidad arquitectónica más recurrente es un espacio cercado por muros en los que al menos uno de ellos posee una estructura escalonada llamada banqueta (Flores op. cit.); estas construcciones ocupan más de la mitad del área del sitio arqueológico. La reiterativa presencia de estas construcciones, el cuidado que tienen los elementos que la conforman y la superposición de patios de este tipo en un mismo espacio muestran la importancia que tuvieron y la necesidad que existía de renovarlos constantemente; estaría relacionado al carácter ceremonial de la arquitectura.

De acuerdo a Moore la arquitectura refleja el orden político, los espacios públicos reflejarían el uso del poder que a su vez involucra relaciones sociales asimétricas (Moore 1996: 3) menciona que entre los usos de la arquitectura pública se encuentran: ser monumentos conmemorativos, obras para ser vistas y admiradas; escenarios de dramas sociales; concentrar gran cantidad de personas o a un grupo reducido de iniciados. Estas ideas directrices respecto al uso de la arquitectura pública nos servirán de base para entender los patios con banquetas de Pucllana, caracterizándolos como espacios públicos; sin embargo, la gran cantidad de patios funcionando al mismo tiempo nos habla acerca de la importancia y necesidad de estos, por tanto, entenderemos estos patios como espacios públicos destinados a concentración de personas a las que hay necesidad de mostrar las jerarquías sociales existentes para legitimarlas y mantener el orden establecido.

Según Tom Dillehay, el éxito de una elite no sólo depende del uso de la fuerza sino también de la persuasión, el carisma, los hábitos, las exhibiciones de probidad y la celebración de banquetes, pensamos que los patios con banquetas han constituido escenarios de actividades donde las elites demostraban su poder y realizaban acciones que contribuían a disolver las probabilidades de conflicto de parte de las capas sociales dominadas (Dillehay 2005: 25).

Los patios con estructuras escalonadas de Pucllana fueron definidas inicialmente por Segundo Vásquez en 1984, en el marco de los trabajos del Proyecto Arqueológico Huaca Pucllana; calificó estos espacios de «grandes patios con un sistema de estructuras escalonadas compuestas de dos largas banquetas apoyadas sobre un muro que sirve a manera de contención o espaldar de mayor altura» (Vásquez 1984: 9) Como otra 
característica se menciona la presencia de restos de postes o al menos los agujeros donde estos estaban ubicados, la disposición de estos parece indicar que se techaba la estructura escalonada; además plantea que estos recintos poseían un carácter palaciego y ritual basándose en la presencia de los escalonados que se pueden observar como un símbolo religioso que esconde las jerarquías sociales; esto lo respalda con la evidencia de figuras moche donde se observa a personajes de alto rango sentados en estructuras escalonadas que reciben a otros de menor rango que se quedan en el nivel inferior (Ibíd.)

En la fecha que Vásquez analizó, se habían reportado cinco estructuras, tres de las cuales fueron descritas; las estructuras se fueron incrementando en las temporadas de excavación posteriores, reportándose en diferentes áreas; las ubicadas en la gran pirámide fueron resaltadas por Isabel Flores, quien recalca la importancia de las banquetas, especialmente las ubicadas al lado Oeste y del uso de la pintura amarilla.

La importancia de este tipo de estructura es resaltada igualmente por José Canziani, quién rescata los planteamientos de Vásquez; además menciona que el tipo de construcción piramidal está relacionado a patrones constructivos de sitios Paracas de la costa sur (Canziani 2009: 289).

En general la presente investigación considera a los patios con estructuras escalonadas como parte principal de los espacios públicos donde se materializan las jerarquías sociales a través de la exposición de los distintos estamentos sociales en posiciones predeterminadas en reuniones cuyos detalles aún desconocemos. Veremos a continuación si la evidencia de la arquitectura y los contextos respaldan esto.

\section{Definición del patio con estructuras escalonadas}

Para los propósitos de esta investigación se ha procedido a analizar 32 patios con estructuras escalonadas de un total desconocido ${ }^{1}$. Es difícil definir la cantidad total de patios observables hoy debido a dos factores: las numerosas remodelaciones que han sufrido y la destrucción que impide definir unidades arquitectónicas así como el hecho de hallarse algunas en la ladera de la pirámide y no se puede recoger medidas y otros datos de ellas. Cada patio posee un número correlativo sin connotación cronológica (Fig. 1). Las variables para el análisis están referidas a su ubicación en el contexto arquitectónico del sitio dejando de lado la sectorización arbitraria; la presencia, descripción detallada y número de elementos arquitectónicos como muros, postes, hoyos, banquetas, pisos, rampas y escalinatas; los rellenos de clausura y la presencia de ofrendas en este o sobre el piso de las patios; finalmente, se analiza las construcciones que se hallan encima y aquellas que fueron selladas para dar paso al patio estudiado.

La descripción de cada patio se basará en las características formales de la arquitectura; el orden de presentación está basado en la secuencia general de la arquitectura, en el cual se ha diferenciado tres fases constructivas de acuerdo a los elementos usados en la elaboración de los muros; además se ha tratado de correlacionar con la secuencia de la cerámica del sitio y los fechados radiocarbónicos.

Independientemente del tiempo y el material constructivo podemos sintetizar la manera como se construye uno de estos patios con estructura escalonada, así. Una superficie plana de forma rectangular debe ser preparada colocando una base de tierra grumosa que tendrá un enlucido de uno a seis $\mathrm{cm}$. de espesor, cuando está listo se agregan los muros de acuerdo a lo planificado. Los cuatro muros que definen el espacio pueden ser construidos con el objetivo de delimitar el patio o alguno de ellos puede

1 Este tipo de patio se ha diferenciado de los patios que no tienen ninguna estructura escalonada, los cuales igualmente abarcan un gran porcentaje del área y muchas veces se encuentran debajo o cubren los patios con estructuras escalonadas. Para el presente estudio tampoco se ha considerado dos recintos de menor tamaño que los patios, ubicados en el Complejo Noreste; los cuales tienen en uno de sus lados banquetas de baja altura y sin acceso, los cuales debieron tener una funcionalidad distintas a la de los patios. 


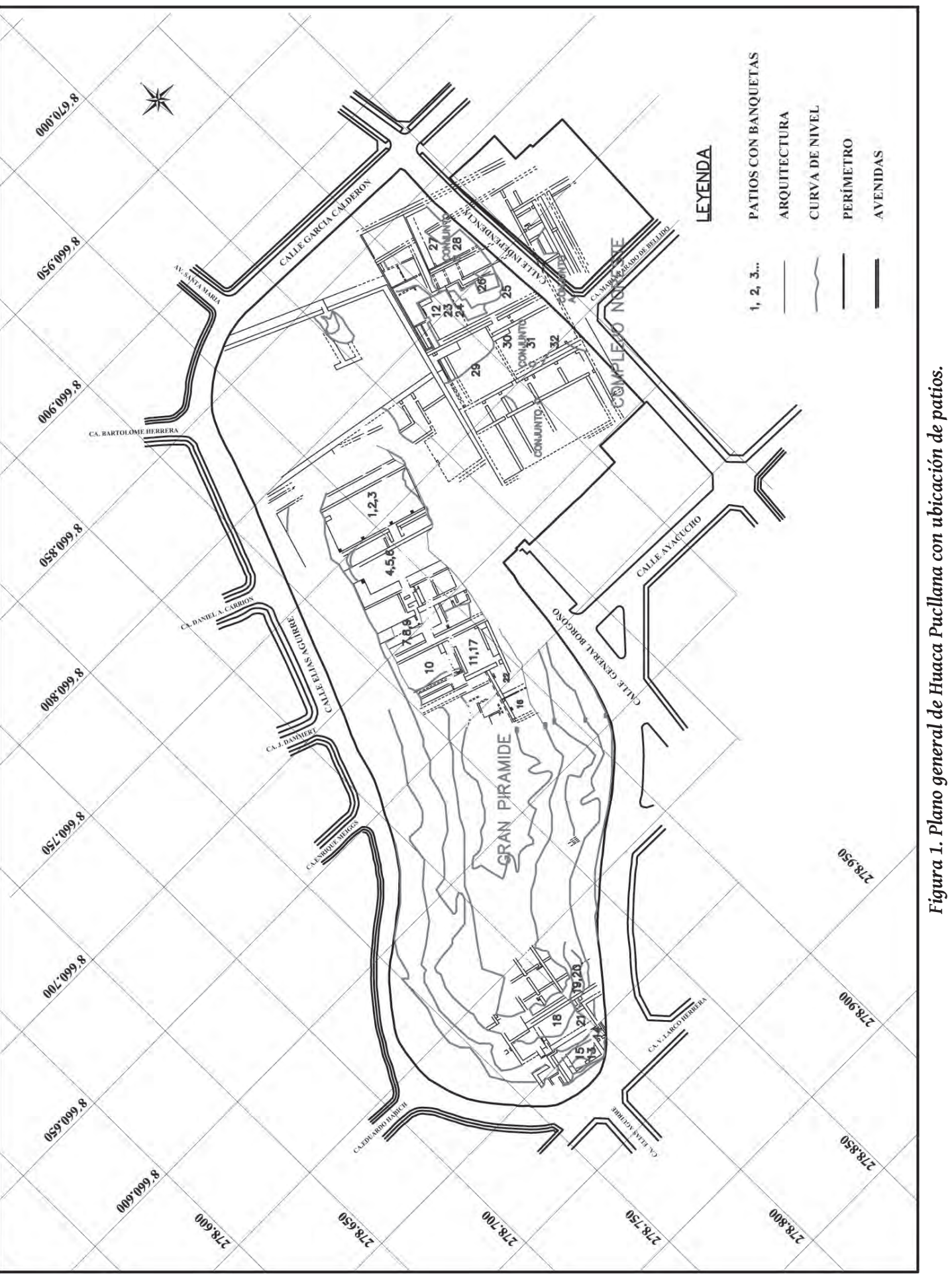


haber quedado de una etapa constructiva anterior, en este caso pueden ser reforzados o ver aumentada su altura. En el caso de los muros nuevos de adobes, se coloca primero una capa de adobes en soga como base y encima se continúa con la técnica del librero. No queda claro si los patios con estructuras escalonadas son el objetivo final de una construcción planificada o los espacios en los que se ubican anteriormente han servido a otro diseño que implica solo un espacio rectangular, observamos esto en algunos muros que se encuentran con enlucido antes de que se añadan las estructuras escalonadas.

Luego se construyen las banquetas, pueden ser de un nivel, dos o ser muy complejas; la forma de construcción de estas banquetas, pueden ser de dos tipos. Usando un murete de adobes paralelo a un muro, la altura del murete es casi la del escalonado y entre éste y el muro hay una distancia variable de acuerdo al ancho que se le quiera dar; este espacio se rellena con adobes, cantos rodados, arena gris o una mezcla de estos elementos. El segundo tipo es hecho sólo con adobes; en ambos casos se enluce y puede ser pintada de amarillo al igual que el muro que le sirve de respaldar. En el diseño debe estar ya incluida la presencia de escaleras o rampas.

En el piso se abren agujeros para colocar postes de madera de hasta $20 \mathrm{~cm}$ de grosor, los que se distribuyen ordenadamente en todo el patio, en filas y columnas, formando ambientes hipóstilos. Se colocan apoyándose en su diámetro más angosto, es decir invertidos; se plantea que los cercanos a las banquetas sostuvieron un techo mientras que el resto deben haber tenido una función distinta. El techo debió ser un armazón de madera, cañas y esteras, probablemente cubiertos de barro, restos hallados en algunos espacios respaldan esta hipótesis. La fase final de la construcción de una estructura escalonada parece haber sido el pintado de todo el ambiente; algunas veces se observa repintados y grafitis.

\section{Descripción De las estructuras escalonadas a lo LARgo Del TIEMPo}

En Pucllana se han definido tres grandes fases arquitectónicas definidas a través del tipo de material constructivo (Flores 2005: 54-56). La primera fase está relacionada a tapiales que habrían formado un edificio piramidal de planta cuadrangular ubicado al extremo sur del sitio. La segunda fase se caracteriza por el uso de adobitos hechos mano de forma paralelepípeda cuadrangular, las construcciones con este material se superpone al tapial aunque no por ello se deja de usar el tapial incluso en las últimas etapas de la tercera fase; esta última fase se caracteriza por el uso de adobitos hechos a mano de forma paralelepípeda alargada, con este material la pirámide alcanza su máximo crecimiento; también con este material son las construcciones del Complejo Noreste. Se define la presencia de patios con estructuras escalonadas en todas las fases, siendo las de la última las mejor conocidas y conservadas. Presentaremos una propuesta de cronología relativa y absoluta de los patios con estructuras escalonadas planteando las principales variaciones.

Para la elaboración de esta secuencia se ha definido los patios que pertenecen a determinada fase constructiva del sitio; agrupados de esta manera en tres grandes etapas; se continúa viendo los espacios físicos definidos sobre los cuales se realizan una o más construcciones, los que poseen patios con una clara superposición entre sí. Finalmente, se ha intentado establecer relaciones entre estos espacios de manera directa (por asociación física) e indirecta (similitud de patrones). De este modo obtenemos un conjunto de secuencias parciales que se pueden asociar entre si mostrando una panorama general de la evolución de los patios desde las etapas más tempranas hasta la desaparición de esta construcción.

\subsection{PATIOS DE LA PRIMERA FASE CONSTRUCTIVA}

Se ha definido la presencia de tres patios con estructuras escalonadas construidos con tapias en el extremo sur de la gran pirámide (Patios 13, 14 y 15). El material constructivo indica la pertenencia a la primera fase; dentro de esta podemos establecer cierta cronología basada en la superposición de la arquitectura, de esta manera podemos decir que los patios 13 y 14 son contemporáneos y el 15 se 
superpone al 13. Los tres se encuentran incompletos, pero, se ha logrado calcular el área aproximada de ellos. En los patios más antiguos el área varía, hay uno grande de probablemente mide más de 1000 $\mathrm{m}^{2}$ y los otros de apenas más de $100 \mathrm{~m}^{2}$, esta diferencia notable debe estar referida a su funcionalidad y puede descartarse como un cambio cronológico pues, el patio 15 que es posterior, tiene poco más de $100 \mathrm{~m}^{2}$. Una muestra de sólo tres patios nos imposibilita plantear cambios en el tiempo relacionados al área de estos. En los tres casos sólo se ha logrado exponer una pequeña sección de estos y se ha calculado áreas hipotéticas.

En ningún caso se han conservado los cuatro muros, se presume que todos debieron tener una altura común que ha sido estimada en cuatro metros aunque en la actualidad ninguno llega a dicha altura, pero hay que tener en cuenta que han sido parcialmente desmontados para las siguientes remodelaciones. El Muro Norte está ausente en los tres patios y no podemos saber si tuvo accesos o banquetas, aunque es posible proponer la presencia de un acceso en caso que no haya restos de esto en los otros. El ancho de los muros varía entre $1,20 \mathrm{~m}$ y 3,40 m. Todos han tenido pintura amarilla en ambos paramentos y no hay restos de grafitis. Una característica del enlucido y la pintura es que poseen un estuco muy delgado que a veces no sobrepasa de $0,5 \mathrm{~cm}$. Las tres banquetas asociadas a este tipo de muros han sido hechas de barro siguiendo las mismas técnicas de los muros de tapial. Las tres se encuentran adosadas a los muros Sur y están pintadas de amarillo teniendo un ancho variable entre $1 \mathrm{~m}$ y 2,20 m. Su longitud varía entre 7 y $17 \mathrm{~m}$ de longitud dependiendo del ancho del patio pues, al parecer, ocupan todo el ancho de estos. Se accede a las banquetas por medio de rampas que se insertan en la banqueta y tienen un tamaño pequeño pues no pasan de un metro de largo y su altura varía entre 0,30 y $0,70 \mathrm{~m}$. Se hallan a cualquiera de los dos extremos de los patios, nunca en le centro.

El piso no presenta mayores detalles tiene un grosor de entre 9 y $20 \mathrm{~cm}$. No hay presencia de hoyitos $^{2}$ y presenta algunos desgastes naturales que evidencian el tránsito que sufrieron durante su uso.

Solo en el patio 14 se ha conservado el acceso al Sur a un recinto; es un vano de forma trapezoidal invertida, cuya parte inferior tiene un metro, y en la parte superior se observan las improntas del dintel, que pudo ser de madera. Consideramos que la ausencia de hoyos asociados al único vano conservado no es prueba suficiente para decir que no existieron puertas (Fig. 2).

En los tres patios hay evidencia de los rellenos con los que fueron clausurados, se trata de bloques de una superficie de suelo estéril que fue cortado, estos bloques parecen corresponder a un suelo con escasa humedad sin restos de vegetales; además hay presencia de tierra suelta y arena ${ }^{3}$. Existe una notoria ausencia de material cultural en estos rellenos que no permite fechar estilísticamente estas construcciones; es posible relacionar esto a la tradición de templos limpios del formativo de la costa central. En términos de asociación entre los patios podemos señalar que el 15 se superpone al 13, este último a su vez, se asocia directamente al 14 que está a su lado Este. Existen otras construcciones de tapia que no han podido ser definidas debido al avanzado estado de destrucción o por tener encima las construcciones de la fase II. Sin embargo, es viable en un futuro cercano poder plantear una propuesta hipotética de la forma del edificio durante la fase I de tapias, esto debido a que consideramos altamente probable que el muro respaldar de la banqueta del patio 13 haya sido el límite Sur del edificio de tapias, uniendo esto a la evidencia dispersa que aparece entre los adobes de la segunda fase se podrá tener ideas más claras respecto a esta fase. Es conveniente agregar la existencia de otro tipo de relleno en las estructuras de tapia, si bien no están directamente asociados a los patios moti-

2 Nos referimos a hoyos pequeños de $5 \mathrm{~cm}$ de diámetro y $15 \mathrm{~cm}$ de profundidad, que son comunes encontrar en los pisos de patios de la tercera fase constructiva.

3 Se puede establecer que la presencia de bloques de suelo árido al sur implica que en esa dirección el suelo no había sido irrigado, de acuerdo a esto podemos decir que en este tiempo el canal Surco y sus ramales no existían en las dimensiones que llegan a alcanzar en tiempos tardíos. 


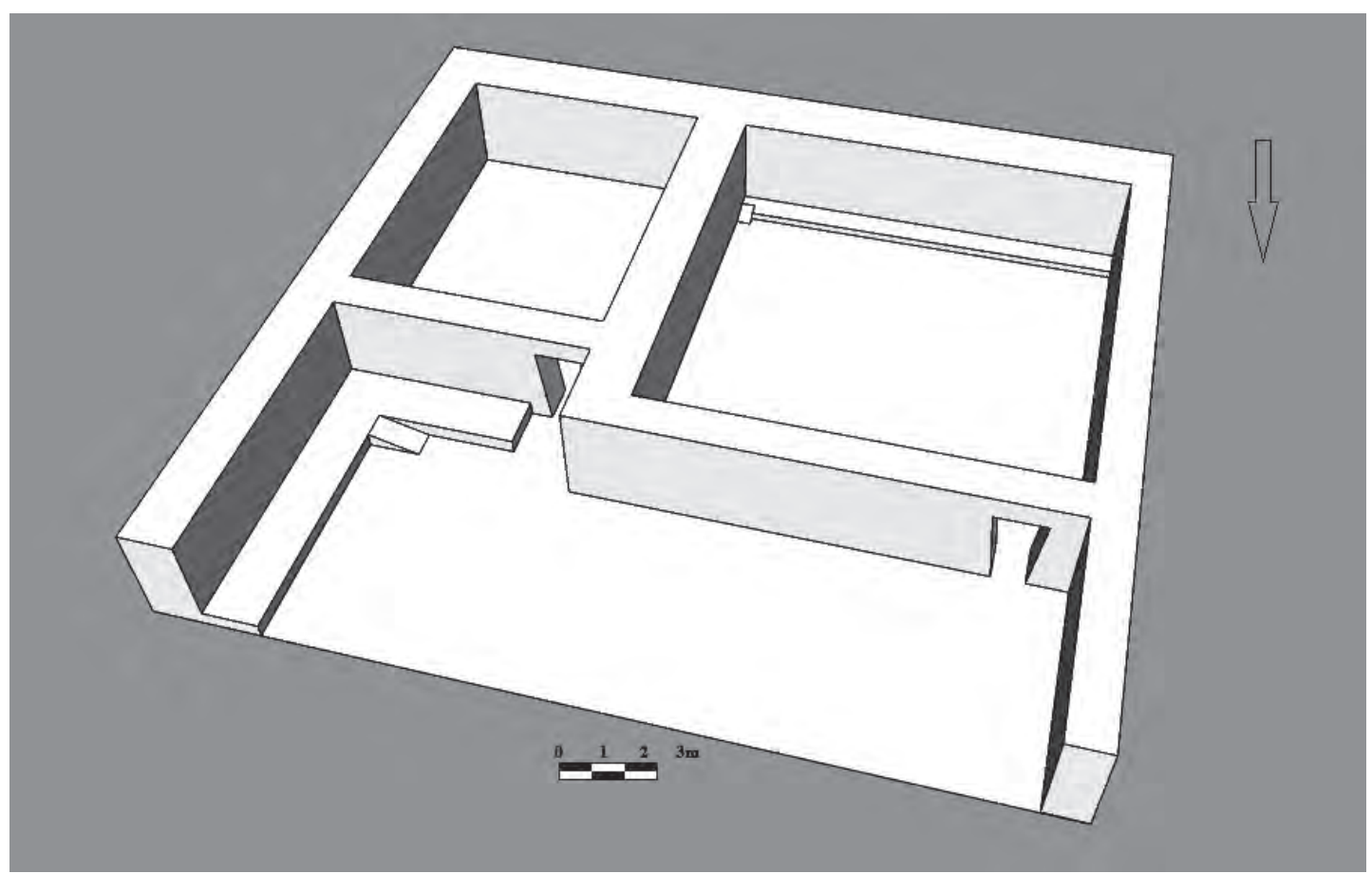

Figura 2. Reconstrucción isométrica del patio 14, primera fase constructiva.

vos de esta investigación. Se trata de adobes irregulares, semejantes a los que se observan en Huaca Huallamarca, perteneciente al Formativo Superior (Valladolid 1992: 134); de estos no existe ningún muro en Pucllana y sólo se encuentran como relleno.

El único material cultural asociado, hasta el momento, es gran parte de un cántaro mamiforme con hombros pronunciados y decoración de diseños entrelazados hallados sobre el piso del patio 14. Perteneciente a la fase 5-6 de la secuencia de Patterson, esto lo ubica en Lima Medio pudiendo decirse que el edificio de tapial es contemporáneo a la vasija. La presencia de esta vasija rota sobre el piso parece ser la primera evidencia del rompimiento ritual de vasijas realizado al inicio de las remodelaciones arquitectónicas tan populares en la última fase constructiva de Pucllana. Se tienen dos fechados radiocarbónicos que se asocian al sello de los edificios de tapia, estos indican las siguientes fechas: $534 \pm 36$ y $550 \pm 43$ (sin calibrar) ${ }^{4}$. Esto nos permite fechar de manera hipotética el final de la fase de tapiales en el $540( \pm 40)$ d.C. No siendo posible establecer, de momento, una fecha de inicio. ${ }^{5}$

Es interesante resaltar que en esta época ya empiezan los rellenos masivos de edificios Lima, si bien es difícil calcular el volumen en ausencia de datos precisos acerca del área, al ver la altura de los muros nos damos una idea de lo que fue el relleno de estos edificios. En el caso del patio 13 ha sido expuesto en un área de $23,5 \mathrm{~m}^{2}$, con una altura estimada de $4 \mathrm{~m}$, estamos hablando de $94 \mathrm{~m}^{3}$ de bloques de barro, siendo probable que este patio haya tenido $1000 \mathrm{~m}^{2}$ de área que corresponden a un trabajo colectivo de alta organización.

4 El primer fechado mencionado está codificado como AA78241, el segundo como AA78243, Los análisis fueron realizados en el NSF-Arizona AMS Laboratory.

5 Pero definitivamente fechan el inicio de la siguiente fase constructiva de adobes paralelepípedos cuadrados, como se verá más adelante. 
Los patios de tapial expresan la concepción básica del patio con estructuras escalonadas que verá su mayor popularidad en la fase III, es importante hacer notar que se trata de obras, casi, estáticas, y su uso debió ser prolongado pues las remodelaciones internas son inexistentes, el espacio es clausurado para construir otro encima, del mismo tipo, pero en cada uno de ellos no hay remodelaciones menores de ampliación de banquetas, etc.

\subsection{PATIOS DE LA SEGUNDA FASE CONSTRUCTIVA}

Se ha definido la presencia de cuatro patios con estructuras escalonadas (Patios 18, 19, 20 y 21), construidos en base a adobes de forma paralelepípeda cuadrangular $(16 \times 16 \times 9 \mathrm{~cm})$ en el extremo Sur de la gran pirámide. El material constructivo indica la pertenencia a la segunda fase del sitio. Estos adobes se usan en un aparejo que podemos llamar de «librero» mostrando la parte más delgada al exterior y en posición vertical. Los muros se forman mediante paneles de forma trapezoidal que se adosan unos a otros.

Al interior de esta fase se puede establecer cierta cronología al observar la superposición y asociación de los patios entre sí y con otros elementos. El patio 21 se superpone directamente al 18 y este es contemporáneo con los patios 19 y 20 debido a que se encuentran al mismo nivel. El área disminuye conforme las remodelaciones rellenan espacios anteriores; por ejemplo, el patio 18 posee $544 \mathrm{~m}^{2}$ y el 21 que se construye encima se reduce a $343 \mathrm{~m}^{2}$; mientras tanto, contemporáneo al 21 tenemos a 19 y 20 con $141 \mathrm{~m}^{2}$; lo cual quiere decir que hay patios grandes y pequeños en un mismo momento.

Sólo en uno de ellos se ha logrado conservar los cuatro muros, es el patio 21 con muros de 0,90 $\mathrm{m}$ a 2,30 $\mathrm{m}$ de ancho en la base pudieron haber tenido entre 2,5 y $4 \mathrm{~m}$ de altura. Sobre el resto de los muros se puede decir que debieron tener una altura similar; en los patios 19 y 20 el ancho en la base varía entre 1,25 y 2 m pudiendo haber tenido una altura de entre tres y cuatro metros. En el caso del Patio 18 el muro del lado Oeste posee un ancho distinto a cada lado del vano que tiene al centro, en un caso es de 1,6 $\mathrm{m}$ y en el otro de sólo 0,8 m. Todos han tenido pintura amarilla en ambos paramentos. El enlucido y la pintura poseen un estuco muy delgado que a veces no sobrepasa de 0,5 cm.

En esta fase las banquetas van a asumir una complejidad que se va a mantener en tiempos posteriores, se agregan elementos de acceso a la banqueta tales como el escalón insertado, desapareciendo (en apariencia, ante falta de evidencia) las rampas. En los patios 18, 19 y 20 las banquetas son simples o compuestas de dos niveles sencillos; se accede a ellas, al menos en el caso de la 18, por medio de escalones insertados en ellas; ninguna supera los 0,90 $\mathrm{m}$ de altura y el ancho está entre el medio metro y 2,1 m. Todas están pintadas de color amarillo siendo el enlucido que le da soporte a la pintura muy delgado pudiendo observarse la forma de cada adobe de la banqueta.

El caso particular, y más interesante, es el de la banqueta compuesta del patio 21 (Fig. 3). Posee cinco niveles superpuestos y una complejidad que no se iguala en la siguiente fase. En un primer nivel hay una banqueta, que aparentemente se extiende a todo lo largo del muro, de 0,30 m de alto se accede a ella por medio de un escalón insertado; esta banqueta posee en la parte central un nivel nuevo también de $0,30 \mathrm{~m}$ de alto al que también se accede por un escalón insertado sólo que esta vez este elemento aparece hacia el Sur y el Norte y no hacia el Este como en el primer nivel. Este segundo nivel tiene adosado a cada lado una saliente de menor altura, de forma alargada pegada al muro de respaldo. Pegado al respaldar pero, sobre el segundo nivel hay otra pequeña banqueta de $0,30 \mathrm{~m}$ de alto pero de menor longitud que a su vez posee otra más encima de la misma altura y también de menor tamaño. Todo el conjunto resalta por su complejidad pero se puede entender en algo la manera como debió ser usado a través del seguimiento de los escalones insertados en las banquetas. El destino parece ser el segundo nivel al que se llega primero poniendo un pie sobre el primer escalón del frente, una vez en la superficie de la primera banqueta se accede al segundo nivel por medio de un escalón que está orientado hacia el Sur, no es probable que se haya ascendido más pues los últimos niveles son angostos y parecen ser decorativos, al igual que los que sobresalen a los lados. 


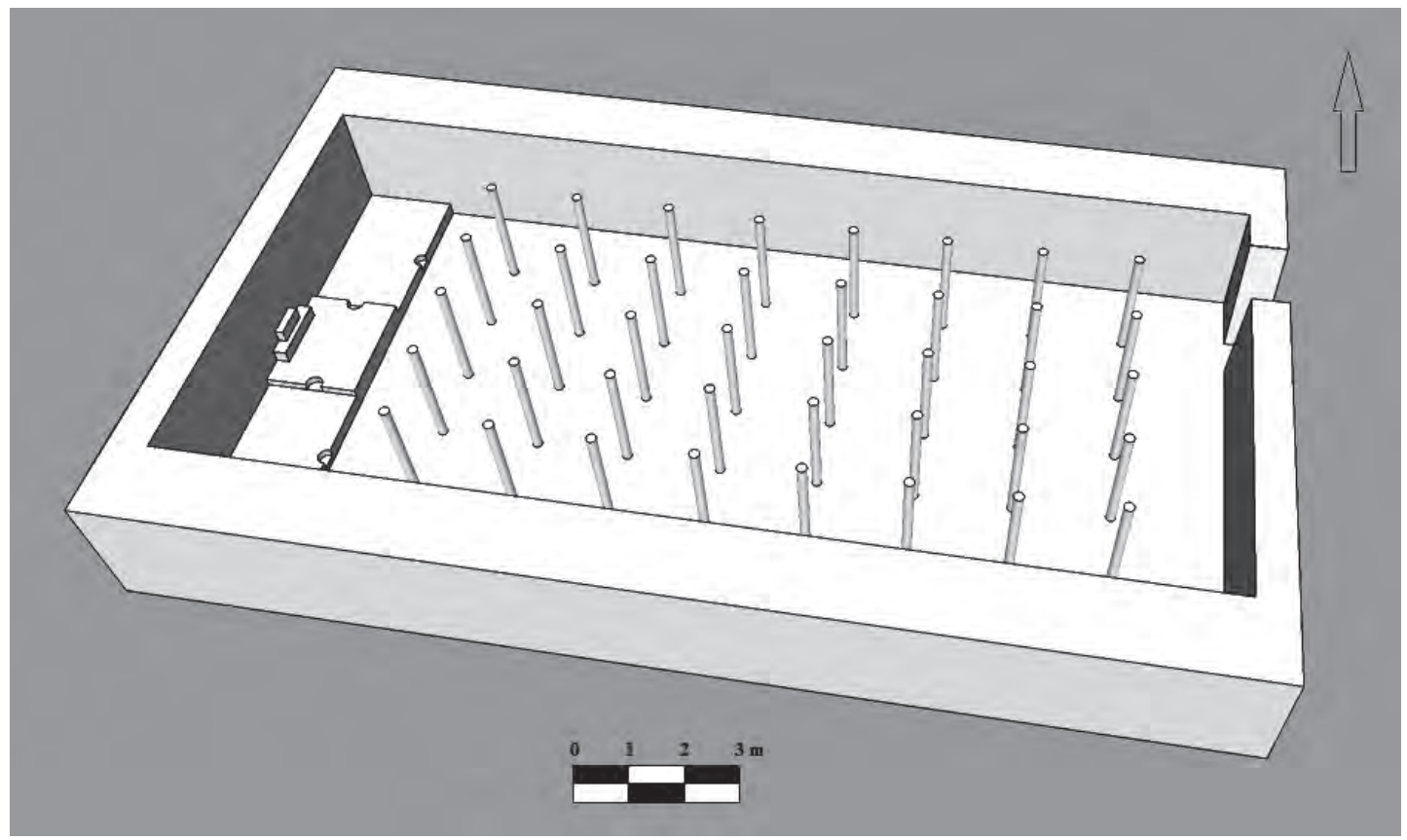

Figura 3. Reconstrucción isométrica del patio 21, segunda fase constructiva.

Los patios 19 y 20 tienen las banquetas hacia el Sur mientras que la 18 y la 21 las tienen hacia el Oeste, dado que la 19 y la 20 son contemporáneas a la 21 podemos decir que no hay sustento cronológico para un cambio en las posiciones de las banquetas al interior de la misma fase. Pero, si es claro que respecto de la fase I de tapias hay una variación y es que además de mantener las banquetas al Sur estas las empiezan a colocar también al Oeste.

El piso no presenta mayores detalles teniendo de grosor entre 8 y $10 \mathrm{~cm}$. No hay presencia de hoyitos y solo algunos desgastes naturales que evidencian el tránsito que sufrieron durante su uso. Respecto de los pisos de la fase I hay cierta disminución en el espesor. En el caso de los patios 19 y 20 no ha quedado restos del piso. Una novedad en esta fase y particularmente en el patio 21 es la presencia de postes, se trata de madera de guarango de un grosor promedio de $0,25 \mathrm{~m}$. en este caso hay un total de 30 repartidos en cinco columnas y seis filas.

Sólo uno de los patios de esta fase ha conservado sus accesos en buen estado, se trata del patio 18 que, tiene uno de sus accesos con características peculiares, se trata de un acceso ciego. Este patio 18 tiene el acceso ciego al Oeste, formado por un muro que se prolonga hacia el Este y voltea hacia el Norte, de manera que no es posible observar el interior de manera directa, al seguir este acceso ciego uno se encuentra con una banqueta; existe otra al Sur la cual, al parecer, se desea ocultar al menos de primera intención. Este patio posee otro acceso ubicado hacia el NE, el ancho de ambos varía entre 0,90 y 1,1 m. En las plazas 19 y 20 se ha descubierto parte del acceso que se ubica al NE pero no se ha logrado obtener mayor información por hallarse aún cubierta de relleno esa área. En ninguno de los casos hay evidencia de postes en los vanos. Al parecer la ubicación de los accesos en esta fase es siempre al Este o al Oeste al igual que en el único caso reportado para la fase I.

En la segunda fase arquitectónica tenemos un cambio radical en el sistema de rellenos, ahora se usa un "emparrillado» hecho con muretes de adobes y rellenados con cantos rodados y arena gris. Esto es común en los cuatro patios analizados, los rellenos cubren la altura total de las banquetas. En el caso particular del patio 21 se clausura, construyéndose un muro que tapa la banqueta en toda su 
longitud y luego el espacio resultante es rellenado; esto parece reflejar una clara intencionalidad de «borrar» la existencia de ciertas partes de los patios de manera drástica. Otro caso peculiar de relleno lo tenemos en los patios 19 y 20, fueron rellenados y en el piso que sirve de sello final al patio se esparcieron algunas cuentas de Spondylus y fragmentos de dumortierita. ${ }^{6}$

En general, la arquitectura de adobes paralelepípedos cuadrangulares se superpone a la de tapias y es probable que el edificio resultante haya mantenido casi la misma área que el anterior pero, definitivamente tomó una altura mayor, se desconoce los sistemas de acceso y las fachadas debido a la destrucción ocasionada por la habilitación urbana realizada en los alrededores en décadas pasadas. La presencia de los patios con estructuras escalonadas desde la primera fase hasta la tercera lo que nos lleva a plantear que a pesar del tamaño sensiblemente menor del edificio en las dos primeras, la forma en general debió ser muy similar a la que se observa actualmente con niveles escalonados donde los patios y los sistemas de accesos en rampas ocupan casi todo el espacio disponible.

Tenemos cuatro fechados radiocarbónicos que se asocian: los ya mencionados asociados al sello de la arquitectura con tapia de la fase 1 , que datan del $540( \pm 40)$ d.C. que a su vez sirven para fechar el inicio de la fase que describimos ahora. Además de esto, contamos con otras dos que se asocian al sello de las estructuras de adobes paralelepípedos cuadrados, justamente obtenidos de un relleno de desechos que cubre el patio 21, estos fechados indican $581 \pm 36$ y $587 \pm 36$ (sin calibrar). Esto nos permite fechar, de manera hipotética, el final de la segunda fase en $585 \pm 36$ d.C. ${ }^{7}$ Por tanto, la segunda fase habría tenido una duración de aproximadamente 40 años. Un dato interesante acerca del sello de esta arquitectura es la presencia de una gruesa capa de desechos en la que abunda la cerámica, los moluscos, restos de textiles y otros materiales culturales acumulados en delgadas capas superpuestas sobre el relleno que cubrió el patio 21. A su vez, este sello de desechos es roto para colocar entierros humanos, al parecer de miembros de la elite Lima colocados sobre camillas y con ofrendas diversas. La cerámica asociada a este sello muestra marcadas diferencias respecto de la que se asocia a la tercera fase, el acabado es más fino y los diseños recuerdan las características de las fases medias del estilo Lima. Sobre este sello de desechos y entierros lo que hay es un gran relleno de cantos rodados con arena gris sobre los que luego se levantará la arquitectura de la tercera fase. Resulta tentador pensar en que el fin de una fase arquitectónica esté ligado al fin de una dinastía o elite gobernante que es enterrada en el sello de lo que fue el edificio desde donde ejerció el poder.

El volumen de rellenos usados, el esfuerzo y el trabajo organizado se mantienen y se ven ampliados si recordamos que el edificio aumenta considerablemente en altura en esta fase. En el caso de la plaza 18, para dar paso a la 21 se le selló con más de $2700 \mathrm{~m}^{3}$ de relleno. Para las plazas 19 y 20 no se ha podido definir el volumen pero siendo contemporáneas a la 21 es probable que hayan pasado por una situación análoga a esta que entran en desuso al final de la fase y son clausuradas por más de $80 \mathrm{~m}^{3} \mathrm{de}$ relleno, esto no toma en cuenta los desechos que son colocados luego encima.

Podemos hallar un cambio en la concepción de la arquitectura en esta fase, deja de ser «estática» para pasar a ser remodelada con algo más de recurrencia, esto se puede ver en el paso de la plaza 19 a al 20 cuya única variación es la forma de la banqueta pero, esto implica ya una necesidad de cambio que no se observaba en la fase I de tapias. Aunque los cambios no son considerables, son interesantes pues marcan la transición con la obsesiva tradición de remodelar estos ambientes que se verá en la tercera fase.

6 La dumortierita es un mineral cristalino de coloración variable, siendo el azul el color con el que se presenta en los contextos de Pucllana. Es también reportado por Régulo Franco (2010: 610) para el Templo Viejo de Pachacamac.

7 El primer fechado mencionado está codificado como AA78239, el segundo como AA78240, Como los anteriores, los análisis fueron realizados en el NSF-Arizona AMS Laboratory. 


\subsection{PATIOS DE LA TERCERA FASE CONSTRUCTIVA}

La tercera fase arquitectónica de Huaca Pucllana está definida por la presencia del uso de un nuevo material constructivo que es el adobe de forma paralelepípeda rectangular alargada $(21$ x 14 x $7 \mathrm{~cm})$. Se conserva el tipo de aparejo en forma de «librero» de la fase anterior pero la arquitectura cobra dimensiones verdaderamente monumentales. En algunas secciones de los edificios de esta fase se observa el uso conjunto de adobes paralelepípedos rectangulares y cuadrangulares, aunque estos últimos aparecen en escaso número; es probable que provengan de muros desmontados.

Las construcciones de esta fase se distribuyen en todo el sitio, por lo que es necesario diferenciar los que se ubican en la gran pirámide, con los que están en las construcciones bajas, área denominada como Complejo Noreste.

\subsubsection{Patios de la tercera fase constructiva localizadas en la gran pirámide}

La complejidad de la Gran Pirámide en esta fase, y su volumen, hace necesario mencionar ciertos detalles de los trabajos realizados en ella. Lo que observamos actualmente es lo que queda tras el abandono Lima, las tumbas Wari, las ofrendas y tumbas tardías, la nivelación colonial para construir una atalaya, el saqueo republicano, ser explotada para obtener barro para fabricar adobes y ladrillos, el abandono, ser basurero y, finalmente, ser recortada para construir pistas. Por tanto, la forma actual dista de ser algo cercano a lo original del siglo VI d.C. Además, los restos de arquitectura más tardía hallados en Pucllana se encuentran en mal estado de conservación. Los trabajos de excavación realizados desde 1967 han expuesto arquitectura asociada a los últimos momentos de la ocupación Lima del sitio, pudiendo establecerse una pequeña y simple secuencia que más o menos indica esto: sistemas de recintos de los que apenas quedan los adobes de base que se superponen a patios con banquetas. Ambos tipos de construcciones hechas de adobes paralelepípedos rectangulares. Por tanto, nuestra información gira en torno a sólo las últimas etapas de la última fase arquitectónica de Huaca Pucllana.

Se ha realizado excavaciones en las laderas del edificio piramidal, los resultados han sido distintos de acuerdo al flanco trabajado. En la ladera Este la erosión no ha afectado mucho los muros y si bien estos se encuentran destruidos se ha recuperado el núcleo de adobes de los grandes muros laterales de la pirámide; los trabajos en el flanco Sur permitieron definir la superposición de materiales constructivos con los cuales se definió las fases arquitectónicas del sitio ; los trabajos al Norte mostraron los restos de la fachada del edificio bien conservada en la parte baja y sumamente destruida en la parte superior; y finalmente, el flanco Oeste aportó una secuencia arquitectónica muy interesante, debido a la destrucción avanzada del gran muro eje Norte-Sur que formaba la fachada Oeste de la Gran Pirámide. Se puede observar la superposición de patios con banquetas en el perfil, al igual que su separación entre sí por gruesos rellenos de cantos rodados y arena gris entre los cuales se ha reportado entierros de al menos un varón sacrificado y huesos sueltos que pueden corresponder a contextos similares.

En relación a la forma final del edificio se realizó una división en niveles enumerados del uno al siete; pero, hay que remarcar que esto sería válido sólo para las últimas etapas constructivas. Tenemos siete niveles, de los cuales uno fue destruido en los años setenta del siglo pasado, se conservan desde el segundo hasta el séptimo. De estos se encuentran patios con banquetas sólo entre el segundo y el sexto nivel. Estos niveles son ascendentes hasta el sexto y de allí el séptimo baja. Los accesos entre niveles se dan por medio de rampas laterales o centrales, y pasadizos. Los patios ubicados en el Complejo Noreste son lo mismo que lo dicho para la pirámide a excepción de que aquí no queda nada de las últimas ocupaciones.

8 Trabajo realizado por el arqueólogo Fidel Fajardo Ríos. 


\section{Patios con estructuras escalonadas ubicados en la Quinta Plataforma}

El quinto nivel de la Gran Pirámide de Huaca Pucllana se ubica en la parte central de esta y ocupa un área aproximada de $950 \mathrm{~m}^{2}$, los patios con estructuras escalonadas que se han ubicado (3) pertenecen a una de las últimas etapas constructivas y resaltan por su complejidad.

Bajo el patio más antiguo descrito aquí hay evidencia de banquetas y rampas visibles debido a que los rellenos han cedido parcialmente en el área SE haciendo notorio lo que está debajo del piso actual; por esto, en algún momento, que se pueda obtener más información de esta etapa anterior, esta podrá variar.

El patio 10 es el más antiguo en el quinto nivel de la gran pirámide, se encuentra completo y tiene un área de $963 \mathrm{~m}^{2}$, tiene forma rectangular y una orientación longitudinal de Este a Oeste. Se han conservado tres de sus muros, faltando el del lado Oeste, el ancho en la base de estos varía de 1,20 a $2 \mathrm{~m}$ estos últimos debieron llegar a cuatro metros de altura mientras que el de 1,20 que es el del lado Este no debió pasar de 2,8 tal vez. Los tres muros conservados son reutilizados y sólo el del Sur está pintado de amarillo, siendo los otros sólo enlucidos con el color natural del barro (Fig. 4).

Existe una sola gran banqueta de 24,8 $\mathrm{m}$ de ancho y 0,80 $\mathrm{m}$ de altura, se extiende a todo lo largo del lado Este del patio, se accede a ella por medio de una rampa, adosada en parte a la banqueta, de 3,90 $\mathrm{m}$ de largo, 3,60 $\mathrm{m}$ de ancho y $15^{\circ}$ de inclinación, hay evidencia de desgaste en la superficie, se deduce que tuvo mucho uso; las paredes laterales están enlucidas del color natural del barro. Idéntica situación tenemos en la banqueta, sólo posee restos de enlucido, bastante desgastado, al parecer sólo mostraba la cara de los adobes, aunque creemos que esto es improbable.

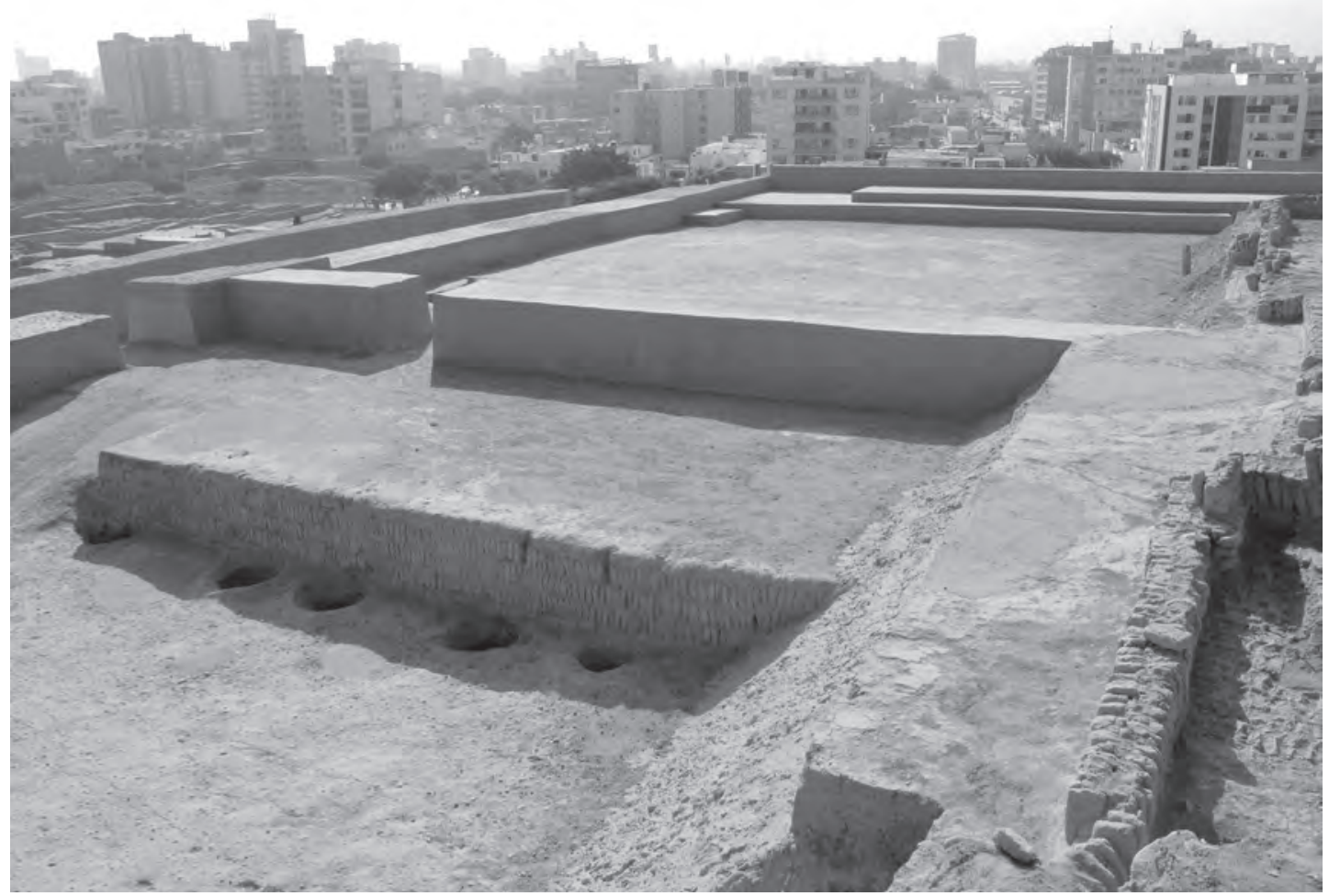

Figura 4. Vista desde la esquina Suroeste del Patio 10 y 17, tercera fase constructiva. (Quinta Plataforma de la gran pirámide). 
El piso posee 0,10 $\mathrm{m}$ de espesor y muestra huellas de desgaste, hoyos pequeños e improntas de tuzas de maíz al Norte, su conservación es regular, ha perdido el acabado en toda su extensión y hubo encima de él abundantes desechos asociados al relleno posterior de este ambiente, con los cuales podría explicarse la presencia de las improntas de maíz. Al extremo Este hay una serie de depresiones al pie de la banqueta en las que, en algún momento, hubo vasijas. Este piso tuvo postes, supuestamente de madera de guarango, ordenados de la siguiente manera: cuatro filas y siete columnas, haciendo un total de 28; se trata de postes invertidos y debieron tener un diámetro de 0,25 m. La distancia entre cada poste es de $3,3 \mathrm{~m}$, siendo este un patrón regular.

Durante este tiempo debió estar funcionando el acceso del SE que tiene $2 \mathrm{~m}$ de ancho; asimismo, es probable que haya existido un acceso en alguno de los extremos del muro del lado Oeste que no se ha conservado.

El espacio ocupado propiamente por el piso, correspondiente a un $48 \%$ del total del patio fue rellenado con $370 \mathrm{~m}^{3}$ de cantos rodados y arena gris, previamente hubo apertura de hoyos pequeños de ofrendas y deposición de basura en grandes cantidades en la que resalta el maíz y huesos de peces, entre ellos dientes de tiburón blanco (Carcharodon carcharias). Esto implicó la desaparición del desnivel preparando el espacio del quinto nivel de la gran pirámide para un patio más reducido asociado a un recinto del cual carecemos de mayor información por la destrucción prehispánica y moderna.

Una vez concluido el relleno y el espacio queda nivelado, se construye un muro que divide en dos ambientes: uno al Oeste y otro al Este; respecto al que está al Oeste se carece de mayor información que un aumento del nivel del piso que será visto luego. El patio 11 tiene un área de $446 \mathrm{~m}^{2}$ y es de planta casi cuadrangular (20,7 x 21,60 m), conserva los cuatro muros que lo definen. El nuevo muro Oeste tiene 1,25 $\mathrm{m}$ de ancho y es probable que su altura haya llegado hasta $2,5 \mathrm{~m}$, posee una banqueta y dos accesos asociados; su acabado es enlucido con el color natural del barro. La situación con los otros muros ya ha sido descrita en lo referido al patio 10.

El patio 11 cuenta con dos banquetas ubicadas en los muros Este y Oeste. La del Oeste se extiende entre los dos accesos ubicados en dicho lado. Tiene 2,15 $\mathrm{m}$ de ancho y 0,40 $\mathrm{m}$ de altura. Su acabado es enlucido con el color natural del barro. La banqueta del Este destaca por su complejidad. Se compone de una banqueta adosada a la esquina NE del patio, de 4,30 $\mathrm{m}$ de ancho y 0,45 $\mathrm{m}$ de altura. A esta banqueta se le adosan una especie de peldaño en el lado NW, este es de $2 \mathrm{~m}$ de largo, $1 \mathrm{~m}$ de ancho y 0,30 m de alto, su función debió ser la de permitir ascender sin mayores problemas al primer nivel de la estructura escalonada. Luego a la banqueta mencionada se le agrega encima otra de solo 3,30 m de ancho que se adosa al muro respaldar pero no tiene contacto con el muro Norte, pues se halla a casi $3 \mathrm{~m}$ de este; pero, termina más al Sur que la banqueta del primer nivel. Todo el conjunto parece estar destinado a permitir el ascenso a la máxima altura en la parte central y Sur de este patio. Este conjunto de banquetas posee como acabado el enlucido con el color natural del barro y ha sido sometida a tratamientos diversos de conservación debido al colapso de la ladera que amenazaba seriamente su existencia.

El piso se encuentra en regular estado de conservación y tiene $10 \mathrm{~cm}$ de espesor, mostrando algunas huellas de quema en su superficie. El rasgo más notorio es la presencia de hoyos de postes y, restos de algunos de estos (en el extremo Sur). Están organizados en cinco columnas de seis y deben ser de madera de guarango y están en posición invertida. La distancia promedio entre ellos es de 2,80 m.

Este patio ha contado con tres accesos: dos al Oeste y uno en la esquina SE; este último es el mismo que el del patio 10 que le antecede. Los otros dos se hallan a cada extremo de la banqueta de lado Oeste, el del Sur tiene casi $2 \mathrm{~m}$ de ancho y el del Norte solo $1 \mathrm{~m}$. Ambos tienen evidencia de hoyos a los lados lo cual implicaría cierta restricción en el acceso.

Los cambios que se dan en este patio para convertirse en el patio 17 son pequeños y tienen que ver con los accesos al recinto del lado Oeste (Fig. 4). En el tiempo del patio 17 el recinto Oeste es re- 
llenado con una capa de 0,30 m de cantos rodados y arena gris, esto implica un volumen de $180 \mathrm{~m}^{3}$, para luego colocarse otro piso; esto, implica un desnivel de poco más de 0,30 $\mathrm{m}$ respecto del patio del lado Este, para solucionar esto se construyen rampas de acceso, la mejor conservada es la del lado NW que tiene 3,40 $\mathrm{m}$ de largo y 0,30 $\mathrm{m}$ de altura con un acabado de enlucido del color natural del barro, en superficie tiene evidencia de desgaste. Fuera de las rampas no hay mayores diferencias entre los patios 11 y 17.

El relleno con el cual se sellaron tanto el patio 17 como el recinto del lado Oeste corresponde a cantos rodados y arena con una altura de $0,80 \mathrm{~m}$ haciendo un volumen total de $768 \mathrm{~m}^{3}$. Sobre esto lo que hay es una sucesión de pisos y desechos, los pisos están con evidencia de uso. El último de estos pisos se asocia con arquitectura que a su vez se puede decir que es contemporánea de los patios 16 y 22 del sexto nivel de la gran pirámide.

Es notorio que este relleno careciera de cerámica vinculada al estilo Nievería en alguna de sus variantes, todo es Lima Tardío, sólo en los pisos posteriores que hemos mencionado aparece el componente Nievería.

\section{Patios con estructuras escalonadas ubicados en la Cuarta Plataforma}

El cuarto nivel de la Gran Pirámide se encuentra al Norte del quinto tras atravesar un pasadizo que contó con accesos laterales ${ }^{9}$. Ocupa un área aproximada de más de $500 \mathrm{~m}^{2}$. Los patios con estructuras escalonadas que se han ubicado (3) pertenecen a una de las últimas etapas constructivas.

El patio 7, que es el inicial, se encuentra construido sobre un gran relleno de cantos rodados y arena gris que sella a un pasadizo laberíntico que tuvo un gran acceso al centro de su muro Norte que será reutilizado en estos patios. Definitivamente, la construcción de estos patios marca un cambio respecto de la arquitectura anterior.

El patio 7 ocupa un área de $392 \mathrm{~m}^{2}$ aproximadamente, se encuentra en la sección central y Oeste del cuarto nivel de la Gran Pirámide, al Este se asocia a un recinto del cual se carece de mucha información por la destrucción sufrida por este. Sólo el muro del lado Oeste no se ha conservado. Tienen de 0,80 a 2 m de ancho en la base pudiendo alcanzar de altura quizás tres meros o sólo dos, dependiendo del ancho en la base. El del lado Norte posee enlucido con el color natural del barro y los del Sur y Este están pintados de color amarillo ${ }^{10}$.

Este patio posee sólo una banqueta al lado Este, tiene 2,40 m de ancho y 0,50 de altura, se encuentra pintada de color amarillo y aparentemente tuvo un escalón como acceso insertado en su extremo Sur; lamentablemente esta situación no es muy clara pues en esa misma área hubo un hoyo que dificulta ver si realmente se trató de un escalón insertado.

El piso se encuentra en regular estado de conservación, tiene 0,10 m de espesor y tiene huellas de quema, depresiones y desgaste en su superficie, los hoyos pequeños están ausentes. No hay hoyos de postes a la vista en esta plaza, suponemos su existencia a partir de la destrucción de etapas constructivas anteriores por la realización de hoyos.

Los accesos se encontraban ubicados al Sur y al Norte en el centro de los muros. El del Norte es reutilizado y tiene 2,60 m de ancho y conducía hacia un sistema de acceso en rampas; el del Sur tiene 2,40 $\mathrm{m}$ de ancho y conducía hacia un pasadizo. Ninguno tiene evidencia de postes por lo que se descarta la presencia de puertas.

9 Las remodelaciones realizadas en esta plataforma fueron descritas en una anterior publicación. (Ríos y Ccencho, 2009).

10 El muro Sur era visible con su altura original de casi tres metros hacia 1967 y en su superficie habían grafitis; para el inicio de los trabajos en 1981 nada de esto quedaba ya. 
El cambio que se da en este patio para convertirse en el patio 8 es grande. El muro del lado Este disminuye su altura a sólo $0,80 \mathrm{~m}$ y pasa a formar parte de una especie de banqueta de gran tamaño de la cual, lamentablemente, carecemos de mayor información por lo avanzado de la destrucción en dicha área. Podemos proponer, de manera hipotética de un nivel alto del patio que se va ampliando notablemente su área hasta ocupar casi toda la superficie del cuarto nivel de la gran pirámide. El resto de muros no sufre mayores variaciones. Sobre la banqueta del lado este se instala una escalera de tres peldaños pintada de color amarillo que asciende de Norte a Sur y se ubica en la esquina SE.

Se añade una nueva banqueta a lo largo del muro del lado Sur, con $3 \mathrm{~m}$ de ancho y 0,50 $\mathrm{m}$ de alto, no se ha conservado ningún elemento que sirviera para acceder a ella. Está pintada de color amarillo y posee un grafiti cerca al acceso.

El patio 9 se diferencia del anterior sólo en la construcción de una rampa en el acceso Sur, de la que sólo quedan restos muy erosionados no pudiendo notarse mayores detalles, parece que es el resultado del aumento del nivel del piso del pasadizo; una situación análoga se ha observado ya en el quinto nivel. Este patio fue cubierto por un relleno masivo de cantos rodados y arena de color gris con los que se niveló toda el área, siendo esto contemporáneo también con el relleno del patio y el recinto del quinto nivel.

\section{Patios con estructuras escalonadas ubicadas en la Tercera Plataforma}

El tercer nivel de la Gran Pirámide se ubica al Norte del cuarto tras pasar un sistema de acceso en rampas. Se ha definido la presencia de tres patios con estructuras escalonadas que ocuparon un área de poco más de $1080 \mathrm{~m}^{2}$. Pertenecen a una de las últimas etapas constructivas del sitio.

El primer patio de este nivel es el 6 y se superpone a un relleno masivo de cantos rodados y arena gris que cubren aparentemente un pasadizo y probablemente un patio con estructuras escalonadas.

Los muros de los lados Este y Oeste no se han conservado, pero su existencia está fuera de dudas, pues uno debió ser el respaldar de la banqueta que allí se ubica (Oeste) y el otro debió delimitar el lado Este. El muro Sur tiene 1,30 m de ancho en la base debiendo alcanzar una altura de 3,5 m, estuvo pintado de amarillo. El muro Norte es el mismo que funciona como respaldar, y muro Sur en los patios del segundo nivel. En general, todos debieron estar pintados de color amarillo.

La única banqueta definida para este patio es de tamaño considerable, mide 21,10 $\mathrm{m}$ de largo por 39,60 m de ancho y tiene 0,80 m de altura; ocupando así el 80\% del área del patio. No observamos la manera como se solucionó el acceso a ella pero es probable que hacia el Oeste haya existido una rampa o una escalera, esta sección no ha sido excavada. En la banqueta se puede apreciar la presencia de hoyos de poste cuando no de algunos de ellos aún conservados, la madera parece ser de guarango y no tienen más de 0,25 m de diámetro. Se distribuyeron en 12 filas de siete columnas haciendo un total de 84 .

El piso se encuentra en regular estado de conservación, tiene seis $\mathrm{cm}$. de espesor y muestra huellas de quema y depresiones. En este patio ocupa apenas un área de $194 \mathrm{~m}^{2}$, aunque desconocemos que ocurre en el extremo Oeste cubierto por remodelaciones posteriores. En el no hay huellas de hoyos de postes a la vista.

Los accesos se ubican al Norte y al Sur. El del Norte comunica directamente con el patio del segundo nivel y mide 3,30 m de ancho, comunica con la banqueta del patio siguiente formando ambos patios una especie de unidad, a pesar de hallarse en niveles distintos; parece respaldar esto el que no hayan restos de hoyos de postes en este vano, lo cual habría implicado presencia de una puerta y cierto control. El acceso del Sur mide 2,60 $\mathrm{m}$ de ancho y comunica con un sistema de acceso en rampas asociado a patios con postes, aquí si encontramos hoyos de postes en el vano.

Luego se añadirán dos banquetas, esto dará origen al patio 4 (Fig. 5). Este mantiene la fisonomía general del patio 6 pero se añade una banqueta al Muro Sur de 3,60 m de ancho y 0,80 $\mathrm{m}$ de alto, se 


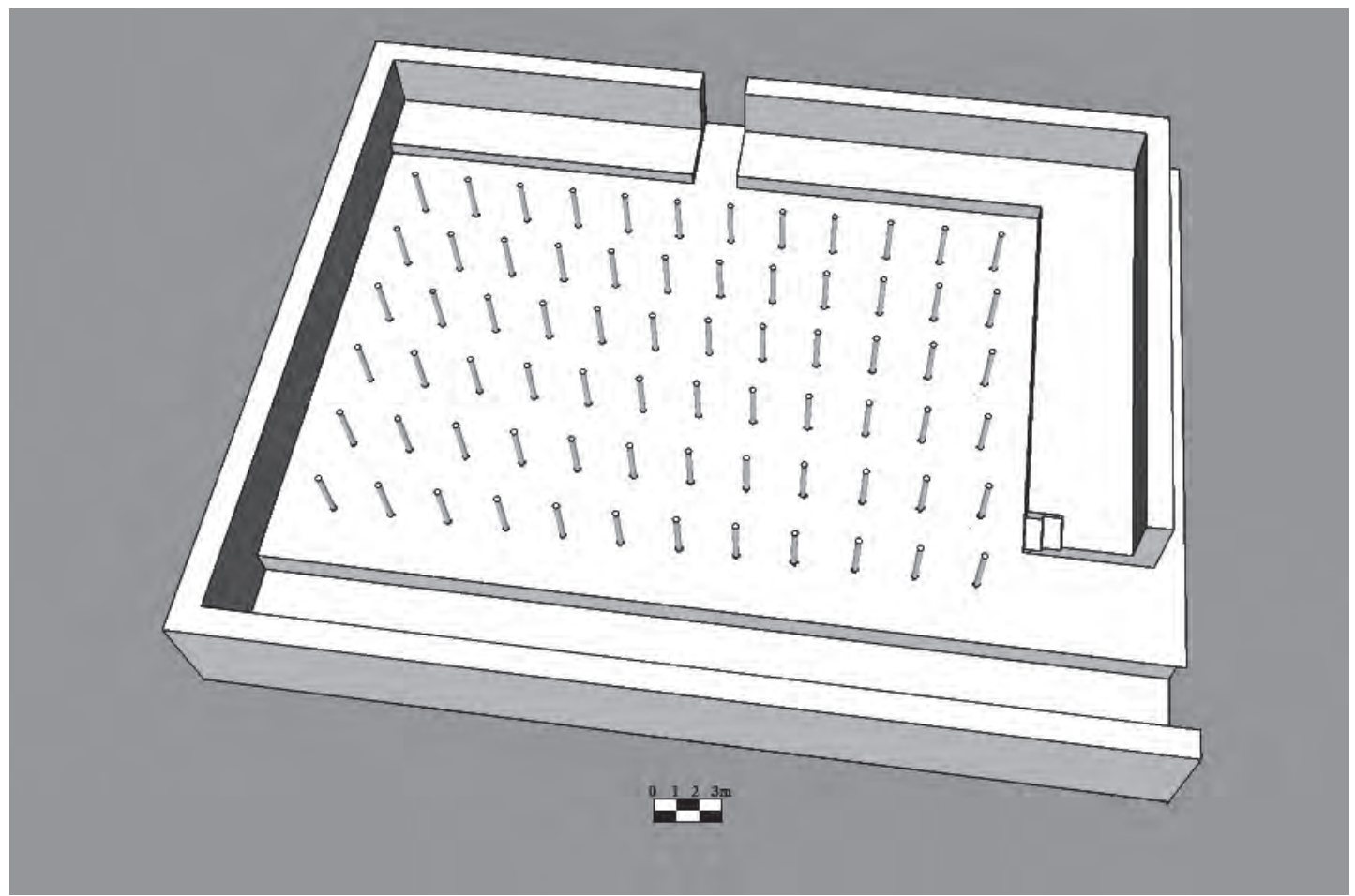

Figura 5. Reconstrucción isométrica del patio 4, tercera fase constructiva. (Tercera Plataforma de la Gran Pirámide).

extiende a todo lo largo del muro Sur; para su construcción se eliminó una fila de postes quedando la cantidad de estos reducida a 72. Al Oeste se adosa una de la misma altura pero con 5,30 m de ancho y una escalera de tres escalones insertada al extremo Norte. Tanto las banquetas como la escalera están pintadas de color amarillo y con un enlucido de casi dos centímetros de espesor. Los accesos y el resto de rasgos permanecen sin variación.

La diferencia que se hace para hablar de un patio distinto; el 5, responde a un aumento de nivel en el sistema de acceso en rampa que se encuentra al Sur para esto se construye una rampa que posee dos remodelaciones. Estas rampas ascienden a una altura de 0,75 $\mathrm{m}$ y la que funciona con el patio es de $3,80 \mathrm{~m}$ de largo y $15^{\circ}$ de inclinación. Este sistema de acceso en rampa del Sur posee varias remodelaciones y parecen responder a necesidades propias del acceso en rampa pues los patios tienen cambios relativamente pequeños.

El patio 5, el último de la secuencia del tercer nivel, fue sellado con un relleno de cantos rodados y arena gris de $0,80 \mathrm{~m}$ de espesor que cubrió toda la extensión del patio a excepción de las banquetas, pues la superficie quedó nivelada a la altura de estas; el volumen de relleno usado fue de $864,9 \mathrm{~m}^{3}$. Encima de esta superficie se construyen sistemas de recintos.

Existe un fechado de radiocarbono que permite datar este conjunto de patios, si bien no está directamente asociado a ninguno de estos. La muestra fue recogida de uno de los recintos del sistema de acceso en rampas que se encuentra al Sur de estos patios, indica $554 \pm 36$ d.C. $(\text { sin calibrar })^{11}$

11 El fechado mencionado está codificado como AA78248, como en los anteriores, los análisis fueron realizados en el NSF-Arizona AMS Laboratory. 


\section{Patios con estructuras escalonadas ubicadas en la Segunda Plataforma}

El segundo nivel de la Gran Pirámide se encuentra en el extremo Norte y ocupa un área de casi 1840 $\mathrm{m}^{2}$ en los que hay una secuencia de tres patios con estructuras escalonadas. Estos patios se construyen sobre un relleno masivo de cantos rodados y arena gris que sella otro patio que se asocia directamente al sistema de acceso en rampa a la Gran Pirámide, este es el único nexo que tenemos para asociar lo que ocurre en la pirámide y en la parte baja.

El patio 1 es el que define todo lo que va a suceder en el segundo nivel de la Gran Pirámide. Se extiende sobre un área de $1838 \mathrm{~m}^{2}$ y conserva restos de los cuatro muros que lo definen. El muro Sur tiene 1,5 $\mathrm{m}$ de ancho en la base y debió tener una altura de 3,5 $\mathrm{m}$, ha sido reutilizado del patio anterior y está pintado de color amarillo. El muro Norte tiene $1,5 \mathrm{~m}$ de ancho en la base y pudo alcanzar 2,5 $\mathrm{m}$ de alto. En la actualidad no conserva ningún tipo de acabado en sus paramentos; pero es probable que este haya sido destruido antes de que todo sea rellenado luego. Del muro Este sólo se observa el paramento Oeste, es el mismo muro que sirve de contención al relleno masivo de cantos rodados y arena gris que selló al patio anterior y el sistema de acceso en rampa. No muestra acabados pero al parecer inicialmente haya estado pintado de amarillo. Estimamos que sobresaldría por encima del nivel del piso del patio 1 en $3 \mathrm{~m}$ del muro Oeste sólo se tiene algunos restos de la base, a través de esto se ha estimado que pudo tener un metro de ancho en la base y 2,5 m de altura máxima. Desconocemos el tipo de acabado que tendría pero es probable que haya estado pintado de amarillo.

Adosada al muro Sur se tiene una banqueta de 3,5 $\mathrm{m}$ de ancho y 0,50 $\mathrm{m}$ de alto, está pintada de color amarillo y no se observa que haya existido ninguna manera de acceder a ella por medio de rampas o escaleras.

El piso está en regular estado de conservación, tiene un espesor de casi 0,20 m y en él se tenían postes de madera de guarango organizados en 14 columnas y seis filas, todos estaban invertidos. Los postes se hallan a una distancia promedio entre sí de 1,30 $\mathrm{m}$ y cada uno no mide más de 0,30 $\mathrm{m}$ de diámetro. Una fila extra se extendía más pegada a la banqueta, formada sólo por doce postes.

El único acceso definido se encuentra al Sur, tiene 3,30 m de ancho y comunica de manera directa con los patios del tercer nivel de la gran pirámide, no hay evidencia de postes que formaran una puerta y restringiera el acceso.

El patio 2 se define cuando se remodela la banqueta del Sur y se añade la del Oeste (Fig. 6). La banqueta del Sur aumenta su tamaño a 1,5 m de altura; para acceder a ella se construyen cuatro escaleras, una de ellas coincide con el acceso al tercer nivel; tienen tres peldaños y están pintadas de color amarillo. Algo interesante respecto a esta banqueta es la presencia de grafitis que han sido realizados cuando aún la banqueta no era pintada, parece que hubieran sido hechos durante el proceso de construcción. Se trata de figuras esquemáticas y abstractas con sólo una representación figurativa antropomorfa. La banqueta del lado Oeste mide 6,80 $\mathrm{m}$ de ancho y tiene la misma altura que la del Sur así como también posee grafitis.

El piso recibe una capa de barro más y se desarrolla en él una actividad de realizar hoyos pequeños rellenados con pequeñas ofrendas, luego son sellados; esto se realiza mientras se construye el piso.

Posteriormente, se rellena el patio hasta ampliar la banqueta Sur en 15,60 m; para esto se construye un murete a esa distancia que posee el paramento Norte pintado de amarillo, pasando a ser ahora esa la cara de la banqueta. Se anula la banqueta del Oeste pero se conserva el resto de muros igual a excepción del Sur al cual se le adosa otro que no está pintado de color amarillo. Este será el patio 3 que como principal característica tiene la de poseer postes dobles, en vez de tener un poste se encuentran estos por pares formando 12 columnas de seis pares, separados cada par entre sí por 1,30 m y al interior de cada par un poste se distancia del otro en $0,30 \mathrm{~m}$.

Todo el conjunto del patio 3 es rellenado por una capa de cantos rodados y arena gris que termina en un piso; el que se encuentra más o menos al nivel del piso que sella, a su vez, las banquetas de los 


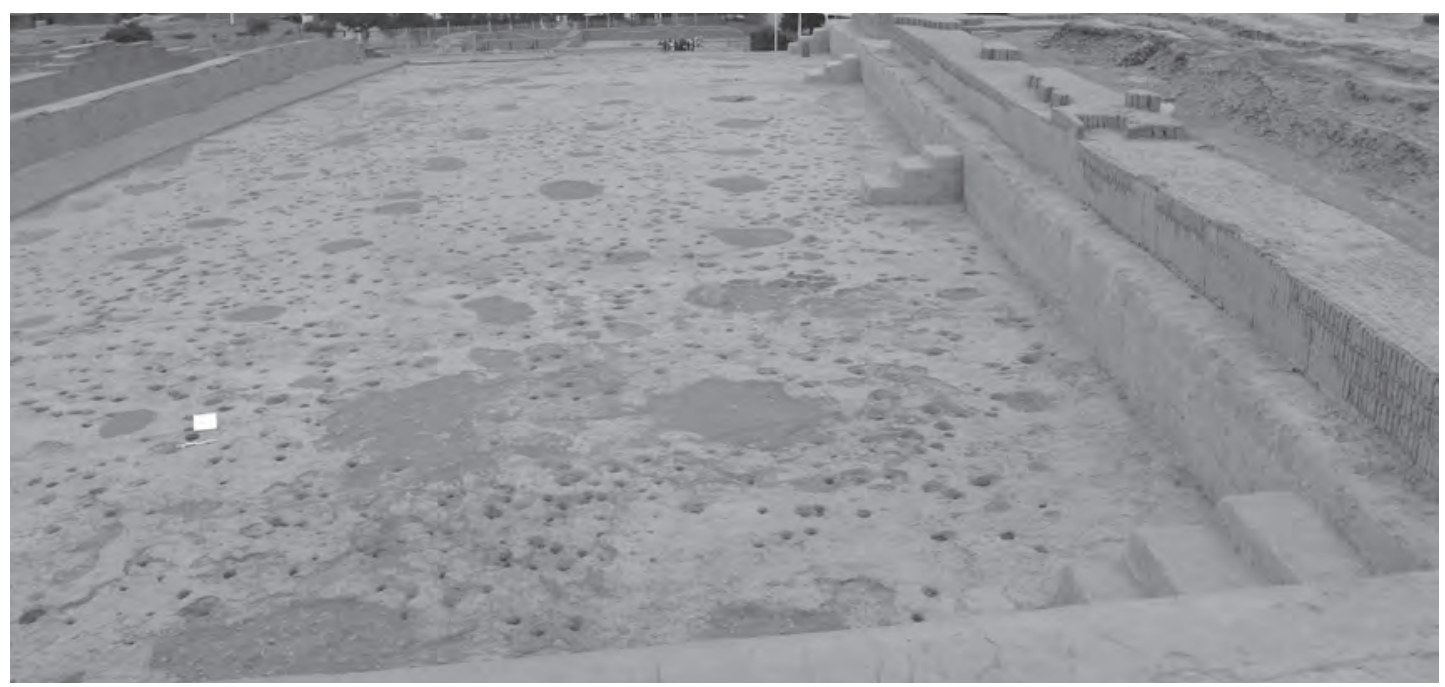

Figura 6. Vista desde el Oeste del patio 2, tercera fase constructiva. (Segunda Plataforma de la Gran Pirámide).

patios del tercer nivel de la pirámide. Lamentablemente desconocemos detalles debido a la avanzada destrucción que esta zona sufrió.

\subsubsection{Patios con estructuras escalonadas de la tercera fase constructiva localizadas en el Complejo Noreste}

El Complejo Noreste, es la parte donde mayormente se han concentrado las excavaciones; definiéndose la existencia de un gran complejo arquitectónico; el mismo que fue construido durante la tercera fase constructiva. Antes de la construcción, los muros presentaban distinta orientación y además se han encontrado evidencias de construcciones hechas con quincha. Este proyecto constructivo está delimitado por el oeste por un gran muro que divide del área de la pirámide y otro muro de similares características delimita el lado Norte y Este; los otros lados están indefinidos por la destrucción del asentamiento. En la parte conservada del complejo se puede distinguir varias etapas constructivas y a la vez remodelaciones; sin embargo, estas han tenido usos similares a lo largo del tiempo; a los que les estamos denominando como Conjunto: A, B, C y D.

El conjunto A, se encuentra al Este, está constituido por el pasadizo que conduce al complejo y un sistema de recintos, que se extiende de Norte a Sur y en el extremo Sur se complementa con otro sistema de recintos que se distribuye en el Conjunto al Sur del Complejo. El Conjunto B, se ubica al Noroeste, corresponde al área de patios; donde se han podido distinguir tres etapas constructivas y muchas remodelaciones, en ellas los patios tienden a reducirse de tamaño a medida que transcurre el tiempo, complementándose en algunos momentos con otros pequeños sistemas de recintos. El Conjunto C, se ubica en la parte media del lado Oeste, se distribuyen patios, que mantienen su diseño y dimensión a lo largo del tiempo y en su etapa más tardía sirvió para acceder por ella a la pirámide. En el Conjunto D, ubicado al Sur, se encuentra un sistema de recintos que tiene la dirección de Este a Oeste.

\section{Patios con estructura escalonada ubicadas en el Conjunto $\mathrm{C}$}

Al Oeste del Complejo Noreste se encuentran los patios 29, 30, 31 y 32. Los patios 29 y 30 son contemporáneos y constituyen, en la práctica una unidad arquitectónica separada por motivos prácticos. El patio 31 se construye sobre el 30 y pasa a funcionar al mismo nivel que el 29, luego, este es sellado y reemplazado por un patio sin banquetas que funciona junto al 32 que se construye sobre el 31. 
El patio 29 está construido sobre un relleno de cantos rodados y arena gris que selló un patio con postes de tamaño mayor. Se extiende sobre un área de $1040 \mathrm{~m}^{2}$ teniendo sus lados de 33 por $31,5 \mathrm{~m}$, tomando así una forma casi cuadrangular. Se conservan los cuatro muros que delimitan su espacio (fig. 7).

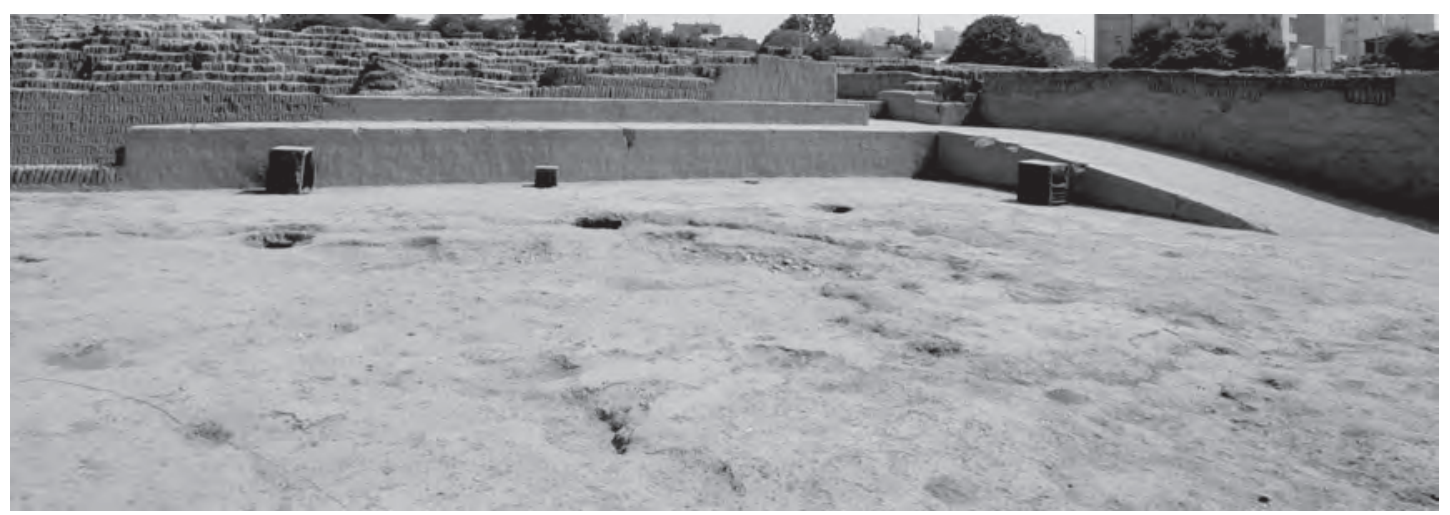

Figura 7. Vista desde el Sureste del Patio 29, tercera fase constructiva (Complejo Noreste).

Los muros tienen entre 1,5 y 1,6 m de ancho en la base, a excepción del muro del lado Este, debieron tener una altura de 3,5 m. Es probable que el del Este haya tenido sólo $1 \mathrm{~m}$ de altura y haya servido más como una marca del desnivel de los dos patios en conjunto ( 29 y 30). Todos tienen un enlucido con el color natural del barro como acabado.

La única banqueta se ubica hacia el Oeste y tiene dos niveles. Su ancho es de 4,20 m y tiene 1,15 $\mathrm{m}$ de alto, se accede a ella por medio de una rampa ubicada a su extremo Norte, esta es de 6,50 m de largo. La ubicación de la rampa coincide con la de un acceso de 2,6 $\mathrm{m}$ de ancho que conduce a un pasadizo ubicado tras el muro respaldar de la banqueta, en este pasadizo hay rampas que ascienden de Norte a Sur y condujeron a un nivel superior al del patio; probablemente en este tiempo la pirámide tenía esta zona como límite Este.

El piso se encuentra en regular estado de conservación con áreas de quema y hoyos de postes, de acuerdo a los que se han conservado podemos plantear que hubo un total de 56 postes de madera (algunos se han conservado, son de guarango) están repartidos en ocho columnas de siete; separados entre sí por 3,90 m, con un diámetro promedio los postes de 0,20 m.

Además del acceso al Oeste hay otro al Este, es una rampa de 2,90 $\mathrm{m}$ de ancho y 7,90 $\mathrm{m}$ de largo, conduce al patio 30 con el cual el 29 debió formar una unidad.

El patio 30 es de forma casi cuadrangular con 24 y 29 m de lado, comparte con el patio 29 el muro del lado Oeste teniendo el resto un ancho en la base de entre 0,90 a 1,6 m y debiendo alcanzar 3,5 m de altura. Todos están enlucidos con el color natural del barro. Sólo hay una banqueta ubicada al Sur, es de dos niveles con un ancho de 3,10 $\mathrm{m}$ y un metro de altura. En el extremo Este posee un pequeño escalón enlucido al igual que la banqueta. El piso se encuentra en gran parte destruido, de lo que se ha conservado se puede observar desgaste; los postes no aparecen en este patio. Debió funcionar junto al patio 29 formando un complejo patio de dos niveles.

El patio 31 es el resultado de sellar el patio 30 hasta la altura de la banqueta con cantos rodados y arena gris. Realizado esto se construye una nueva banqueta al Sur de 3,15 m de ancho y 0,5 $\mathrm{m}$ de alto. Sobre el nuevo piso no hay mayor información por lo avanzado de la destrucción. Este patio 31 funcionó junto al 29 pues queda ya a su mismo nivel.

El patio 32 es el sello del 31 con una nueva capa de cantos rodados y arena gris, se mantiene el patrón general pero se construye una nueva banqueta de 1,60 m de ancho y 0,50 m de alto; pues la anterior ha quedado sellada por el relleno. En este tiempo el patio 29 ha sido sellado también y en su 
lugar hay un patio sin banquetas asociado también al pasadizo con rampa que conduce, probablemente, a la pirámide.

\section{Patios con estructuras escalonadas en el Conjunto B (Etapa Temprana)}

Los patios 12, 23 y 24 constituyen una secuencia de superposiciones y remodelaciones que se desarrollan, al igual que los casos anteriores, en una misma área; para poder ligarlos con el resto de la arquitectura hay que tomar en cuenta asociaciones y proponer secuencias hipotéticas ${ }^{12}$. Lo cierto es que corresponden a etapas tardías de la ocupación Lima de Huaca Pucllana. Fueron construidos sobre una gruesa capa de cantos rodados y arena gris con apisonados intercalados en ella, a partir de la evidencia hallada al NE este relleno podría tener restos de sacrificios humanos.

El patio 12 posee un área de casi $3800 \mathrm{~m}^{2}$ de s cuales se ha logrado exponer menos de la mitad. Sólo se puede observar los muros Oeste y Sur los que tienen un ancho en la base de $4 \mathrm{~m}$ el del Sur y de 1,5 el del Oeste (aunque este se encuentra adosado a otro). Debieron tener una altura cercana a los cuatro metros y poseen un enlucido del color natural del barro. Los otros muros no se observan, el del Este debió ser destruido al habilitarse la calle Independencia y el Norte debe estar debajo de otras remodelaciones.

Adosadas a cada uno de estos muros Sur y Oeste hay banquetas de dos niveles. En el caso de la del lado Oeste tiene $8,80 \mathrm{~m}$ de ancho y 0,70 de alto con otra banqueta más pequeña formando un escalonado de dos niveles. Se accedía a esta banqueta por medio de una rampa ubicada en el centro de esta que tenía una longitud de 6,30 $\mathrm{m}$ y $13^{\circ}$ de inclinación. Esta banqueta tiene un acabado que consiste en un enlucido del color natural del barro. La banqueta del lado Sur es similar pero sólo tiene 3,60 m de ancho y carece de rampa de acceso.

El piso tiene $6 \mathrm{~cm}$ de espesor, está bien conservado pero muestra huellas de quema, desgaste y depresiones. Según el orden de los hoyos hubo 120 distribuidos en 12 columnas de 10, separados por 3,10 $\mathrm{m}$ la madera fue de guarango.

El acceso a este patio no ha sido localizado pero suponemos que debió de estar al Noreste.

Se remodelan las banquetas y se añade una rampa; esto desembocará en la creación del patio 23. Ocupa la misma área que el 12 pero las banquetas aumentan de altura, la del Oeste medirá ahora 1.50 e altura y la del sur 1,20 m conservando siempre la forma escalonada con dos niveles. A su vez, para mejorar el acceso a la banqueta Sur se le adosa una rampa de 5,50 m de largo y $13^{\circ}$ de inclinación. No habrá mayores variantes (Figs. 8 y 9).

El patio 24 será el resultado del relleno con cantos rodados y arena gris del patio 23 hasta el nivel superior de las banquetas. Esto implicó el uso de $4025 \mathrm{~m}^{3}$ de relleno. Se mantiene las banquetas escalonadas al Sur y al Oeste pero estas disminuyen drásticamente su tamaño, alcanzando sólo de 1,60 m a 3,40 $\mathrm{m}$ de ancho y no más de $0,5 \mathrm{~m}$ de altura (Fig. 10). Al igual que los anteriores, este patio posee enlucido con el color natural del barro.

Posteriormente este patio será rellenado con una capa de 0,50 m de espesor de adobes completos y rotos con desechos, sobre ellos se construirá un piso pero la nueva construcción ya no es un patio con estructuras escalonadas sino un conjunto de recintos y patios sin banquetas que nos es difícil definir por el momento debido a que están cubiertos por remodelaciones posteriores.

\section{Patios con estructuras escalonadas en el Conjunto B (Etapa Media)}

Se ubican al Este de lo que fueran los patios grandes pero, sobre una serie de remodelaciones. Son dos patios designados como 25 y 26, se diferencian solo en detalles y se extienden sobre un área aproximada de $900 \mathrm{~m}^{2}$.

12 Esta unidad tiene el número de UA 07 (Ríos, 2008: 123). 


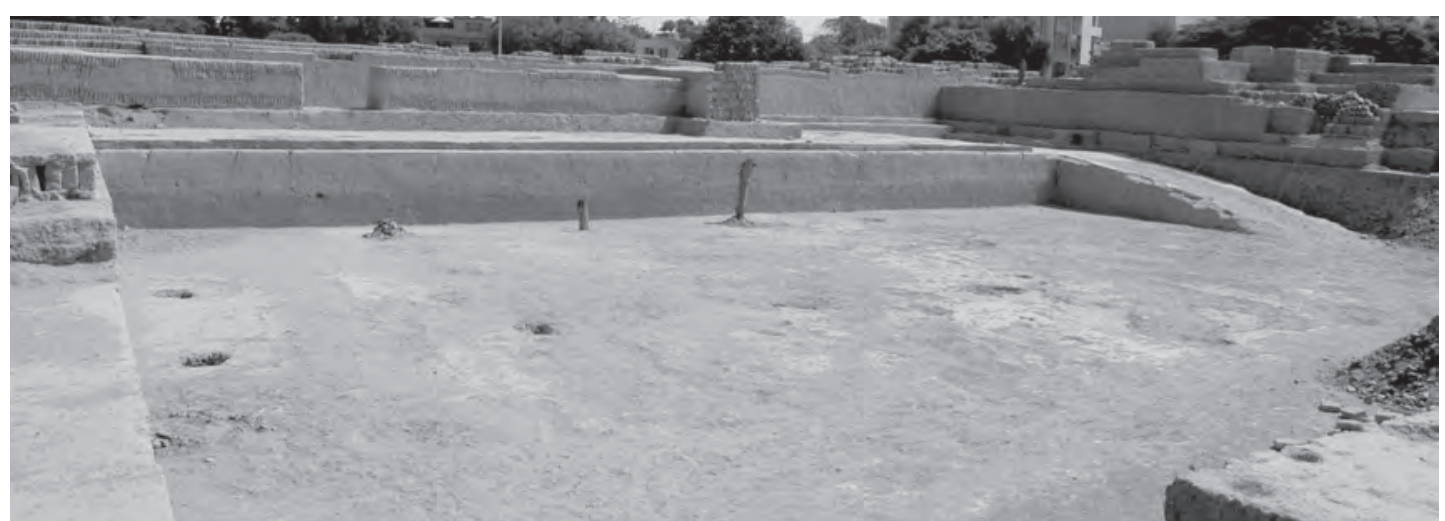

Figura 8. Vista desde el Sureste del patio 23, tercera fase constructiva. (Complejo Noreste).

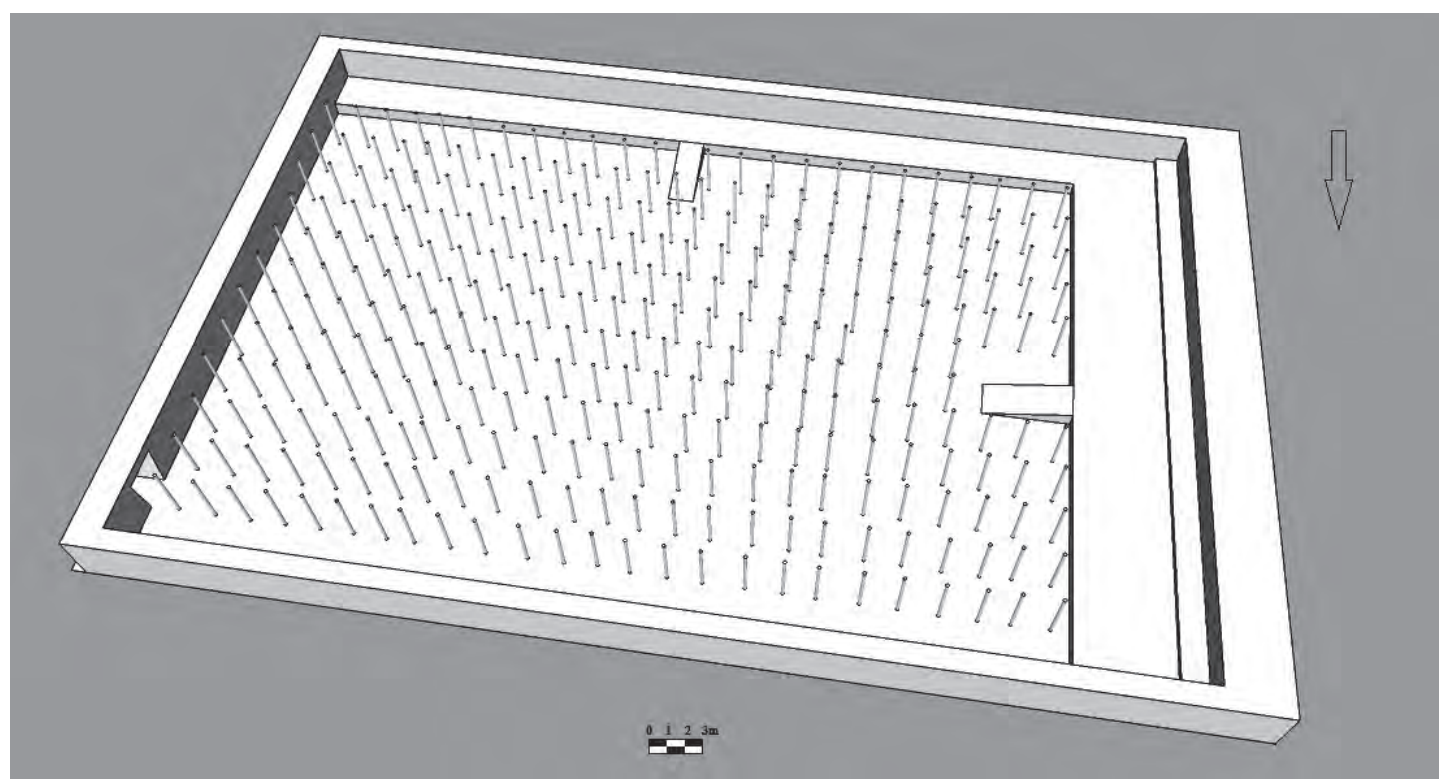

Figura 9. Reconstrucción isométrica del patio 23, tercera fase constructiva. (Complejo Noreste).

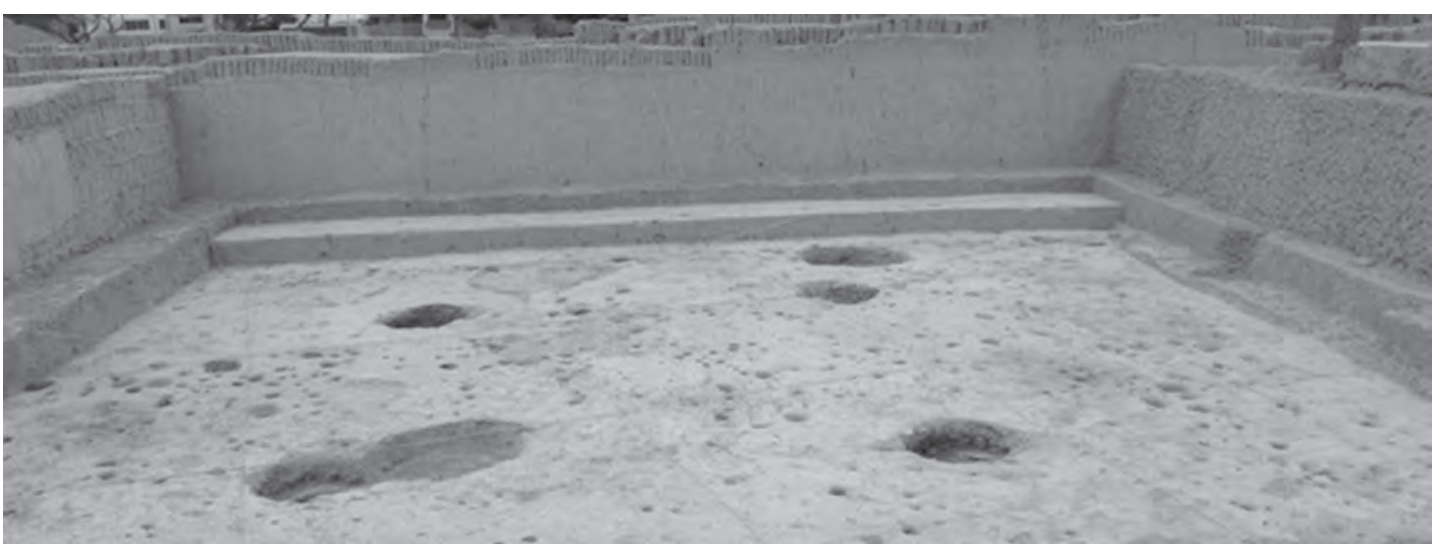

Figura 10. Vista desde el Este de banqueta del patio 24, tercera fase constructiva. (Complejo Noreste). 
El patio 25 sólo conserva el muro del lado Norte de 1,5 $\mathrm{m}$ de ancho en la base pudiendo alcanzar unos 3,5 m de alto. Los lados Oeste y Sur han sido definidos por la presencia de las banquetas que, aunque carecen de respaldar, indican que allí hubo muros; sobre del lado Este no hay evidencias. La banqueta del lado Oeste tiene 2,30 de ancho y 0,80 m de altura, está enlucida con el color natural del barro, resalta lo delgado y descuidado de este. La del Sur tiene 3,60 m de ancho y de altura sólo 0,50 $\mathrm{m}$ carece de la parte superior completa es probable que haya existido un nivel más que haya llegado hasta los 0,80 $\mathrm{m}$ de la banqueta del Oeste. Para acceder a la banqueta del Sur existe una rampa al centro de 2,15 $\mathrm{m}$ de largo y $12^{\circ}$ de inclinación, su acabado también es de enlucido del color natural del barro. El piso se está en regular estado de conservación, tiene 0,10 m de espesor, en su superficie hay numerosos hoyos pequeños de ofrendas. Hay hoyos de postes que debieron estar organizados en cuatro columnas de ocho (32 en total), con 0,20 m de diámetro. Se encuentran a un metro de distancia entre sí de Norte a Sur y a casi tres metros de Este a Oeste. El acceso ha logrado conservarse al NW en el único muro que permanece, tiene $1,5 \mathrm{~m}$ de ancho y estuvo guarnecido por postes lo que implica cierta restricción en el acceso. Fue rellenado con una capa de 0,80 m de espesor de adobes enteros y rotos mezclados con desechos, esto nivela el espacio a la altura de la banqueta de mayor altura.

El patio 26 mantiene, aparentemente, la forma y área del 25 aunque lo avanzado de su destrucción no permite confirmarlo. El piso está en pésimas condiciones al igual que la única banqueta conservada al Sur, esta tiene 0,60 $\mathrm{m}$ de altura desconociéndose el ancho y si tuvo más de un nivel. Se accede a ella por medio de una rampa ubicada al centro de esta que posee $2,5 \mathrm{~m}$ de largo y $15^{\circ}$ de inclinación. En el piso es posible observar que se mantiene el patrón de los 32 postes de madera de guarango como en el patio 25; hay presencia de hoyos pequeños con ofrendas y un área de quema interpretada como horno de cerámica. Se mantiene el acceso en la misma ubicación que el anterior, al NW se reduce el ancho a sólo 0,70 m. este patio fue sellado con un relleno de adobes enteros y rotos de 0,60 m de espesor que dio paso a un conjunto de patios sin banquetas.

\section{Patios con estructuras escalonadas en el Conjunto B (Etapa Tardía)}

Estos patios constituyen los únicos con pintura amarilla en la parte baja de Pucllana. Se construyeron sobre un relleno de cantos rodados y arena gris que sella un pasadizo y un conjunto de recintos y patios anteriores. Bajo este relleno hay una gruesa capa de desechos de los cuales se extrajeron materiales para dos muestras de carbono 14 , los resultados fueron: $578 \pm 44$ d.C. y $562 \pm 44$ d.C. ${ }^{13}$ (sin calibrar); podemos decir que los patios descritos aquí son posteriores a dichos fechados. Ocupan un área de $956 \mathrm{~m}^{2}$ y como única arquitectura asociada existen restos de recintos pintados de amarillo al Sur; estos patios son la evidencia más tardía de la arquitectura de la parte baja de la zona arqueológica.

El patio 27 se extiende en el área indicada conservándose los muros Norte, Oeste y Sur, el del Este fue destruido al trazarse la calle Independencia. Los tres existentes tienen entre 1,15 y 1,30 m de ancho en la base están pintados de amarillo, debieron alcanzar una altura máxima de 3,5 m. El enlucido es grueso, pudiendo alcanzar hasta $1,5 \mathrm{~cm}$.

Posee dos banquetas: una al Norte y otra al Sur. La del lado Norte tiene 1,70 m de ancho y 0,60 m de alto y está pintada de color amarillo. La del Sur tiene dos niveles, el primero con $0,90 \mathrm{~m}$ de alto y 2,5 $\mathrm{m}$ de ancho, el segundo tiene 0,5 $\mathrm{m}$ de alto y 1,60 de ancho, toda pintada de amarillo.

El piso se encuentra en regular estado de conservación, tiene $18 \mathrm{~cm}$ de espesor y con evidencias de hoyos de poste que debieron ser alrededor de 96, de acuerdo a la organización y distancias entre ellos, formados en 8 columnas de 12, cada uno está a 2,90 m del otro y tienen 0,30 m de diámetro.

13 El primero de los fechados está codificado como AA78244 y el segundo AA78245 realizados en el laboratorio mencionado en referencias anteriores. 
No hay evidencia del acceso pero debió estar al Noreste. El patio 28 es una ligera modificación del anterior: se construye una banqueta más, al Oeste y una rampa de acceso a esta que tiene 4,25 $\mathrm{m}$ de ancho y 0,40 $\mathrm{m}$ de alto, también de color amarillo. La rampa se construye en la esquina SW formada por las banquetas del Oeste y del Sur, tiene 2,20 m de largo y 0,40 de alto, ascendiendo de Norte a Sur (Fig. 11).

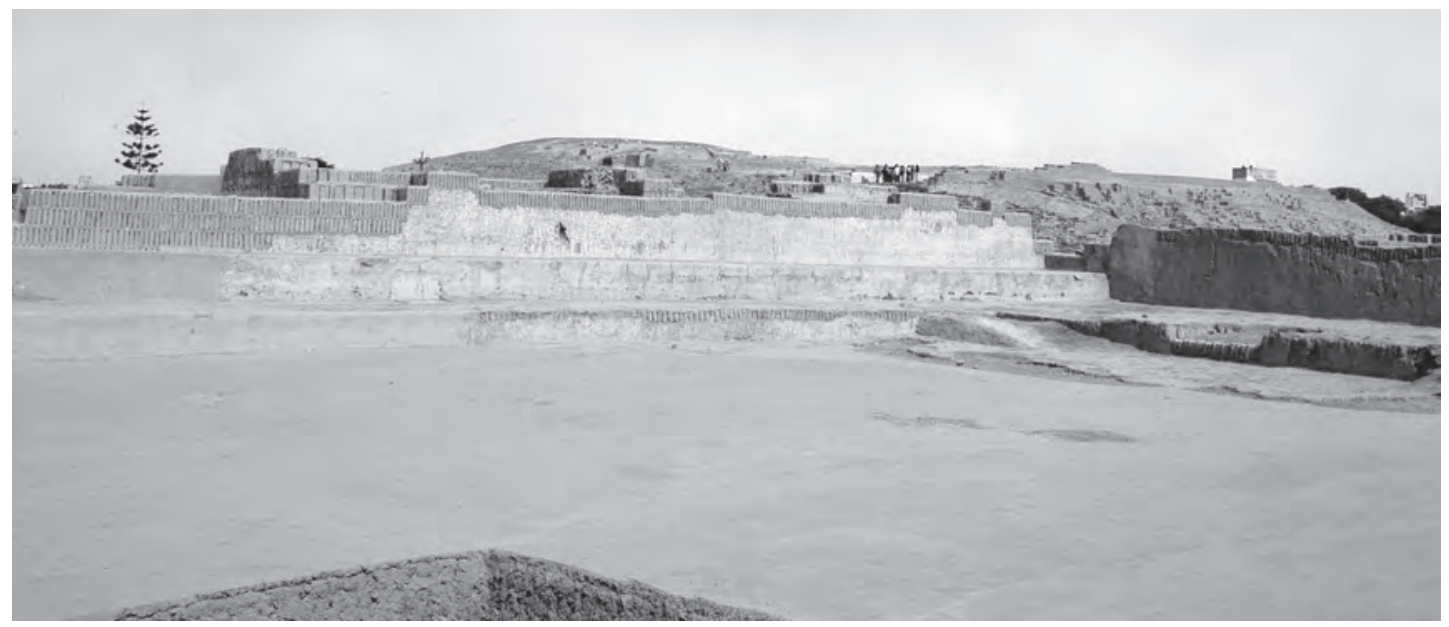

Figura 11. Vista desde el Noreste del patio 28, tercera fase constructiva. (Complejo Noreste).

Posteriormente el patio es sellado con un relleno de adobes completos y rotos junto a desechos, al nivelar la superficie se construye un patio sin banquetas que luego será rellenado con cantos rodados termofracturados, arena gris y abundantes restos de vegetales y carbón. Este sello parece ser el final del sitio y reviste un carácter especial, encima de él ya no existe evidencia de arquitectura y se inicia la destrucción del sitio así como la presencia de algunos contextos funerarios, aparentemente de finales del Horizonte Medio.

\subsection{PATIOS DE LA TERCERA FASE CONSTRUCTIVA (TARDÍA)}

Se ubican al NE del sexto nivel de la Gran Pirámide, que se encuentra a una altura ligeramente menor que el resto, se ha excavado parte este sector con una ligera depresión y el hallazgo ha sido una sucesión de construcciones no muy claras debido al colapso de parte de la arquitectura en la ladera.

Son dos patios (el 16 y el 22), uno de ellos completo y el otro no, contiguos y contemporáneos. El 16 se encuentra en mal estado de conservación y es de forma casi cuadrangular con un área proyectada de $171 \mathrm{~m}^{2}$ mientras que el 22 es rectangular, y casi duplica en área al anterior con $307 \mathrm{~m}^{2}$, del que sólo se ha recuperado y se exhiben $210 \mathrm{~m}^{2}$. La contemporaneidad de estos patios muestra que las diferencias de área no eran un rasgo que varía de manera sistemática con el tiempo.

En ambos casos se han conservado tres muros, el faltante es el del Este debido al colapso que debió sufrir por hallarse en la ladera. El ancho en la base varía entre 0,50 y 1,5 m lo cual nos indica que las alturas eran diferenciadas, los de medio metro de ancho no debieron pasar de 1,5 $\mathrm{m}$ de altura y los otros probablemente llegaron a tres metros. Los muros más delgados se encuentran en el patio 16 que a la vez es más pequeño en área, es probable que haya existido cierta jerarquía entre estos espacios. El acabado de los muros es un enlucido de baja calidad del color natural del barro.

Ambos patios poseen banquetas a los lados Oeste y Sur con pequeñas diferencias. En el patio 16 la banqueta del Sur es muy pequeña, mide 0,60 $\mathrm{m}$ de ancho y 0,40 $\mathrm{m}$ de alto, se ha conservado en un metro de longitud pudo tener una longitud similar a la del muro del respaldar. Su baja altura pudo haber 
hecho innecesario alguna rampa o escalera. La banqueta del Oeste es distinta, mide 2,50 de ancho y $0,90 \mathrm{~m}$ de alto. Para acceder a esta banqueta existe en la parte central una escalera de tres peldaños; la banqueta como la escalera poseen un enlucido del color natural del barro. Esta banqueta posee la peculiaridad que es la presencia de la base de dos construcciones rectangulares, enlucidas; ubicadas en sus extremos. No hay nada similar en el sitio y debieron tener una altura mayor que los $0,20 \mathrm{~m}$ que se aprecian ahora (Figs. 12 y 13).

En el patio 22 la banqueta del lado Sur mide 2,5 $\mathrm{m}$ de ancho, 0,90 $\mathrm{m}$ de alto y se extiende a todo lo largo de su muro respaldar, no hay evidencia de nada que haya permitido ascender a ella; esto debió solucionarse por medio de la escalera que se encuentra al centro de la banqueta del lado Oeste; que posee el mismo ancho y altura, su acceso es una escalera adosada a la parte central, no se sube a ella desde el Este, como ocurre con la del patio 16, sino, desde el Sur. La banqueta y la escalera están enlucidas con el color del barro (Fig. 13).

Los pisos son de baja calidad, el del patio 16 tiene $6 \mathrm{~cm}$ de espesor, la factura es mala así como la conservación, en el patio 22 no se puede apreciar el espesor del piso por la pésima conservación, podemos deducir que también tuvo un espesor mínimo. En ambos encontramos áreas de quema, depresiones y desgaste; hay ausencia de hoyos pequeños, tampoco encontramos presencia de hoyos de postes, debiendo tratarse originalmente de espacios libres sin ningún tipo de techo.

En ninguno de estos patios se ha conservado el acceso; pero, es posible inferir que se encontraban al Este pues los muros de los otros lados no conservan huella de accesos. Los muros del lado Este no se han conservado así que lo planteamos como una hipótesis; pero, de ser así la cercanía de la ladera habría implicado la existencia de un pasadizo con un muro separándolo del vacío.

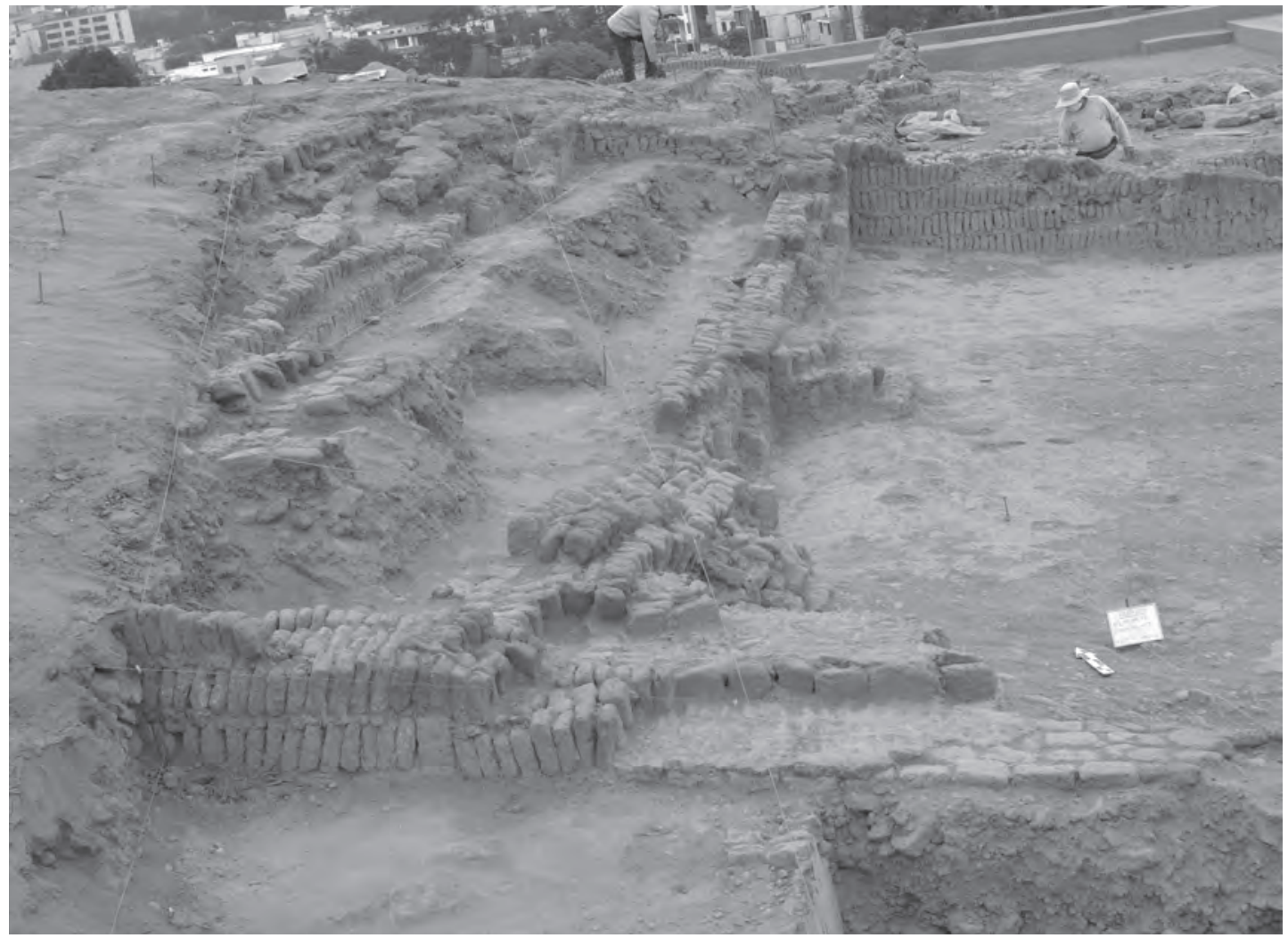

Figura 12. Vista desde el Sur del patio 16, tercera fase tardía. (Sexta plataforma de la gran pirámide). 


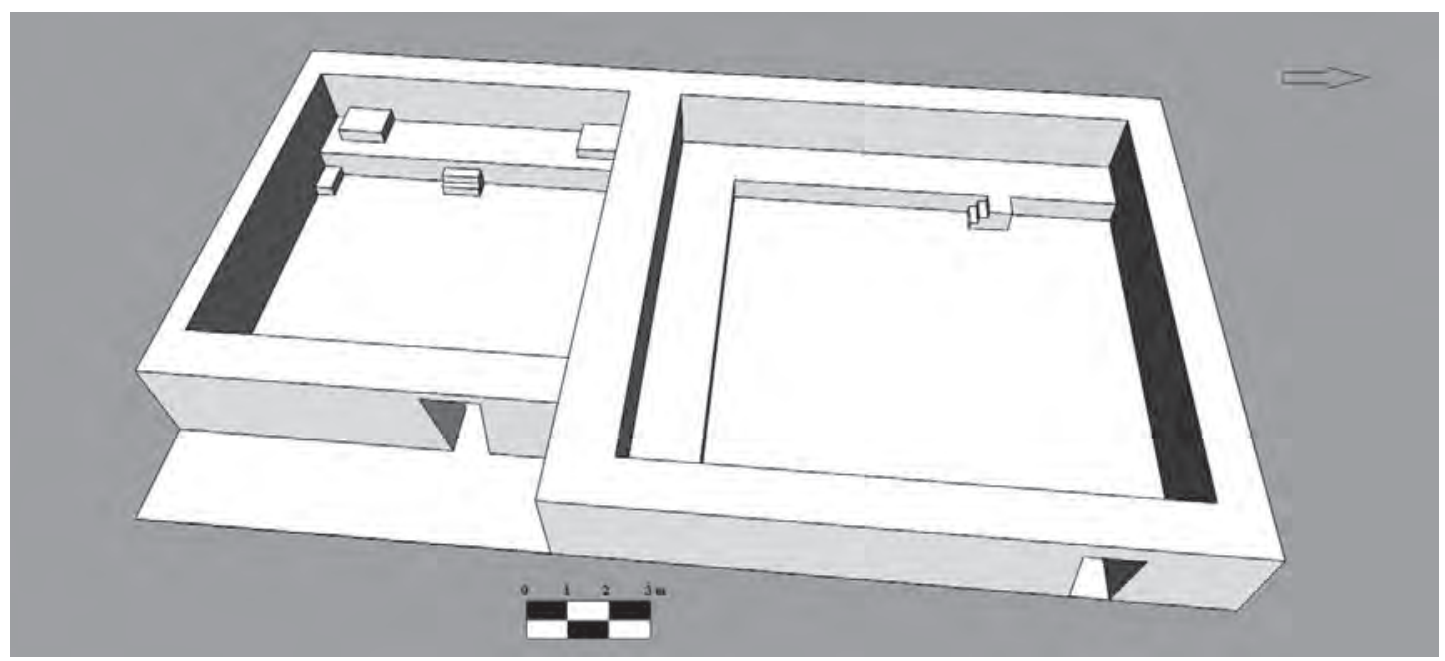

Figura 13. Reconstrucción isométrica de los patios 16 y 22,

tercera fase tardía. (Sexta plataforma de la gran pirámide).

Los rellenos están constituidos por adobes enteros y fragmentados junto a desechos, parecen ser restos de demolición, desconocemos el origen de estos rellenos pero se han definido otros similares en otras partes del sexto nivel de la pirámide.

Estos patios constituyen las únicas unidades arquitectónicas conservadas de la última etapa constructiva de Huaca Pucllana; no es posible, por el momento asociar estos con otras áreas del sitio $^{14}$. Este carácter tardío se ve corroborado por la visualización que se puede hacer de ellos en la fotografía aérea de 1944 (SAN). La arquitectura sobre la que se superponen estos patios no es posible definirla pues se encuentran al borde de la ladera Este de la pirámide con los muros y rellenos colapsados; por otro lado no se ha profundizado bajo sus pisos de manera suficiente. Acerca de las construcciones que pudieron hacerse encima del relleno de estos patios no se ha encontrado evidencia.

En construcciones del quinto nivel de la pirámide se halló cerámica Nievería B (Ccencho 2006) que asocia estas construcciones al Horizonte Medio época 1B. Estas se encuentran al mismo nivel que los patios 16 y 22, aunque desconocemos la forma y funcionalidad de estos recintos, todo indica, que fueron contemporáneos con nuestros patios en mención. Por tanto, podemos asociarlos a la misma época y con el alfar llamado Pucllana Nievería B.

\section{Patios con estructuras escalonadas en otros sitios Lima}

Las estructuras escalonadas se han reportado en diversos sitios de la Cultura Lima; aunque, en algunos casos solo podemos tener referencias por el material gráfico y fotográfico.

En Huaca San Marcos se muestra la existencia de uno de estos patios en la plataforma 3, pertenece a la antepenúltima fase constructiva, aproximadamente del año 500 d.c; esto de acuerdo a una maqueta y su descripción (Shady y Narvaez 1999: 22); resalta que la banqueta de un solo nivel se encuen-

14 Durante la temporada de trabajos del año 2010 se expuso, en la parte más alta del sexto nivel, restos de arquitectura Lima muy tardía que podrían asociarse a estos patios; pero, el avanzado estado de destrucción debido a su superficialidad y las intrusiones de tumbas Wari hacen imposible cualquier correlación, por el momento. 
tra al Sur. También en un plano de Pedro Alarcón se aprecia otro patio con una banqueta al Sur, con acceso al centro (Alarcon 1971); en ambos casos es resaltante la ubicación de las banquetas al Sur.

Del sitio de Makat- tampu, ubicado en Mirones y destruido en 1945, se tienen las notas de campo, consultadas por Mercedes Cárdenas quién lo consideró como un sitio Lima (Cárdenas 1998: 150-152). En este sitio habían varios montículos; de uno de ellos se menciona ambientes hechos con adobitos y otros con adobón (Tello 1999: 118-120); los ambientes con adobitos, estaban enlucidos y pintados de amarillo; los muros presentaban varios desniveles a modo de asientos; se adosaban a ambos lados de una entrada, la altura era de 30 a $60 \mathrm{~cm}$; también se menciona recortes en los bordes en forma de media luna; estas descripciones son reforzadas con una foto publicada por Roger Ravines (Ravines 1994: Foto 171), en la que se aprecia un ambiente con banquetas a ambos lados de un muro con un acceso; además se encuentra dos tipos de escalones, uno empotrado con dos pasos y otro de un solo paso en forma de media luna; este último está relacionado en Pucllana a la época Lima Medio ${ }^{15}$.

En Cajamarquilla Régulo Franco describe algunos patios con banquetas para diferentes conjuntos arquitectónicos y propone una diferenciación temporal de los mismos; todos corresponden al periodo Intermedio Temprano. En el correspondiente a las épocas más tempranas, Fase I de Cajamarquilla, (Franco 1998: 77-78); la banqueta se orienta longitudinalmente de Norte a Sur; y está compuesta por varios niveles. Para la fase II, se reportan en el Conjunto Laberinto, en la plaza principal, (que tiene $2362 \mathrm{~m}^{2}$ ) inmediatamente después de la entrada, y al lado Norte tiene una banqueta de 1,75 $\mathrm{m}$ de altura y $10.65 \mathrm{~m}$ de ancho, a esta se accede por cuatro escalinatas; también se encuentran en nueve recintos, algunos de los cuales están interconectados, el acceso a su superficie es con escalinatas ubicadas en la parte central de uno y dos peldaños; la mayoría de los recintos presentan banquetas en el lado Norte. Para esta misma fase se reporta en el Grupo IV, donde existe una plaza de 20,56 x 22,40 m, con una banqueta en el lado Norte que mide 7,70 $\mathrm{m}$ de ancho, con una escalinata de acceso de cuatro peldaños, ubicados en un extremo; sobre dicha banqueta se ha encontrado poyos cortos adosados a los muros. (Franco 1998: 84). Franco plantea que estas banquetas debieron servir para oficiar y dirigir manifestaciones ceremoniales.

En Pachacamac, Régulo Franco y Ponciano Paredes reporta patios con banquetas en el Templo Viejo; en construcciones correspondientes a la fase constructiva tardía ${ }^{16}$. Las banquetas se distribuyen en el patio principal, en el cual desemboca el acceso principal, dicho patio mide 60 x $50 \mathrm{~m}$; las banquetas se distribuyen en el lado Sur, Oeste y Norte; las del Oeste y Sur tienen $6 \mathrm{~m}$ de ancho y $1 \mathrm{~m}$ de altura; se señala la importancia de la banqueta Oeste por encontrarse otro nivel de banqueta angosta adosada al muro respaldar de $47 \mathrm{~cm}$ de ancho y $30 \mathrm{~cm}$ de altura, además en esta área se encontró evidencias de enlucido con decoración policroma (Franco y Paredes 2000); también se encontraron postes que debieron soportar el techo, especialmente en el área de las banquetas; de acuerdo a la información del dibujo reconstructivo de dicho patio se observa que el acceso a la banqueta Oeste es mediante dos escalinatas ubicadas en ambos extremos (Franco 2005: Fig. 10). Otro espacio con presencia de banqueta es el recinto principal, contiguo al anterior, en el que existen banquetas al Norte y Oeste; mientras que al Sur hay hornacinas; resalta este recinto con respecto a los otros recintos ubicado al Sur, por su tamaño y por encontrar restos de pintura; el del oeste tiene una banqueta de 2,15 $\mathrm{m}$ de ancho y $40 \mathrm{~cm}$ de altura. Los autores resaltan la presencia de banquetas al lado Oeste, pudiendo relacionarse a ceremonias de culto al mar (Franco y Paredes 2000; 2005).

15 En la foto, igualmente se aprecia que los muros fueron hechos con adobe paralelepípedo cuadrangular, similar al de la segunda fase constructiva de Pucllana.

16 Los investigadores han diferenciado modificaciones en el templo, relacionados al empleo de los colores; los cuales corresponden a ocupación del Intermedio Temprano y del horizonte Medio. Para el intermedio Temprano existe una fase temprana, en la cual no existe empleo de color y las estructuras son hechas con piedra y adobitos; la fase tardía, que se subdivide en un primer momento con pisos pintados de amarillo y un segundo momento con pisos pintados de blanco y con empleo de pintura negra para los diseños. 


\section{Comentarios finales. \\ EN BUSCA DE UNA TIPOLOGÍA}

Los 28 patios ${ }^{17}$ de Huaca Pucllana, con estructuras escalonadas pueden ser clasificados por su forma, en cuadrangular y rectangular; abarcando el 70\% el de la última forma; es interesante notar que los de forma cuadrangular se ubiquen en las partes más elevadas de la gran pirámide; y a la vez son los más tardías. Por tanto, podemos señalar que lo más característico de estos espacios es la forma rectangular, ubicándose las banquetas en el lado más alargado; esto se puede generalizar a otros patios de los otros asentamientos Lima.

Los patios pueden ser clasificados por la cantidad de banquetas que contienen; los simples (Figs. 2 y 3), que contiene una sola banqueta corresponden al 50\%, de los que la mayoría se ubican al lado Sur, seguido por el lado Oeste y finalmente el lado Este; los patios compuestos por dos banquetas (Figs. 2, 5, 9 y 13) corresponde al 47\%, la ubicación de las banquetas están en su mayoría al Sur y al Oeste; tienen la misma proporción los que se ubican al Sur y Este con los de Este a Oeste; finalmente los que solamente tienen al Sur y al Norte. Solo hay un patio compuesto por tres banquetas, en el que el único lado sin banqueta es el Este. Podríamos, por lo tanto, resumir señalando que existe una preferencia por construir banquetas en el lado Sur y en otros compartir el Sur con el Oeste. Sin embargo, los que no coinciden en dicho patrón se explica por la ubicación del ambiente en el sistema de circulación de todo el complejo.

Existe una diferenciación por el tipo de banqueta: estas pueden ser de un nivel, de dos niveles y las que tienen otros accesorios. En las de un solo nivel, la banqueta es ubicada al ras del piso y siempre es más amplia que la banqueta más elevada. Banquetas con accesorios, solo se ha reportado un caso, que corresponde a la fase constructiva II (Fig. 3). Las banquetas están asociadas a sistemas de acceso, los que son clasificados en: rampas, escalinatas adosadas y escalinatas empotradas; en el caso de las rampas, su ubicación puede ser en la parte central o a uno de los lados, sus dimensiones está relacionada a la dimensión de la banqueta; en el caso de las escalinatas adosadas, estas presentan generalmente tres peldaños (Fig. 6), aunque también pueden darse solamente de uno; la orientación puede ser de manera directa o apoyarse lateralmente; con respecto a su ubicación estas pueden estar en un lado o pueden disponerse equidistada mente. Las escalinatas empotradas tienen dos formas, las que tienen diseños complejos, a modo de escalinatas de hasta dos gradas (Fig. 5), su orientación es directa, ubicada en una arista y las que están en forma de media luna, de un solo peldaño, ubicadas siempre en la parte central de la banqueta (Fig. 3); estas últimas están asociadas a construcciones de la época Lima Medio. Este tipo de peldaño en media luna puede usarse para fechar el sitio de Makak Tampu (Cárdenas 1998); también las estructuras de Melgarejo (Guerrero 1998), en los cuales aparecen en las banquetas.

\section{La configuración espacial}

Para contextualizar los patios es necesario notar el sistema de circulación del asentamiento, considerado como un centro ceremonial, con una gran pirámide y construcciones en la parte baja denominadas Complejo Noroeste. La entrada al asentamiento estuvo ubicado en la esquina Noreste; allí un pasadizo, orientado de Este a Oeste desembocaba en un complejo arquitectónico, constituido por patios y un sistema de recintos; la circulación en el complejo se realizaba por los patios, primero en sentido de Este a Oeste y luego hacía el Sur, hasta llegar a la parte central del complejo donde el sentido era hacía el Oeste; aquí se produce el primer cambio drástico, ya que el ingreso a la pirámide es un espacio completamente delimitado, el sistema de acceso es en forma de zig zag, combinando orientaciones de Este a Oeste y de

17 En total son 32 patios estudiado, solamente que para este caso se contabilizó 28 patios que se encuentran casi completos; los otros 4 no tenemos la dimensión real. 
Sur a Norte. Ya en la pirámide, el sistema de acceso se inicia en la plataforma 1, ubicado en el lado Norte y luego se dirige hacia el sur, accediéndose a las siguientes plataformas, para alcanzar la plataforma más elevada (Plataforma 6), en cada una de las plataformas existen divisiones de pasadizos que se orientan de Este a Oeste; existiendo fuertes diferencias de nivel hasta en tres secciones hasta alcanzar la más elevada; sin embargo, existiría una comunicación del nivel de la plataforma penúltima hacia la plataforma ubicada más al extremo sur (plataforma 7), que es menos elevada. Podemos concluir que en dicha circulación existe una intencionalidad mayor en su dirección al Sur, combinada con otra al Oeste.

Se puede hacer una relación del proceso de circulación con el lado más importante del interior de los patios; es decir se construyen las banquetas en el lado que presenta mayor importancia. Notamos que la mayor parte de ambientes tienen banquetas al Sur, en cuyo lado existen accesos que conducen a ambientes más elevados, es decir el lugar final del proceso de circulación es casi siempre a lugares cada vez más alto. En los otros ambientes, cuyas banquetas se ubican en los otros lados, los ambientes tienden a presentar autonomía, pero siempre la parte más importante se encuentra en el sentido opuesto al del acceso; es decir cuando una persona ingresa al ambiente lo que observará en su frente será la banqueta.

En Huaca Pucllana la orientación de la pirámide es al Norte pero con 15 grados al noreste; esta orientación ha sido resaltada anteriormente por Franco, quién compara las orientaciones para sitios de Huaca San Marcos, Pachacamac y Cajamarquilla (Franco 2005: 86). A esto podemos agregar la pirámide principal de Catalina Huanca ${ }^{18}$ y de Melgarejo (Guerrero 1998); aunque se ha tratado de generalizar que la orientación de las pirámides Lima son de Este a Oeste, proponiendo que son similares a las pirámides de la época Paracas encontradas en el valle de Chincha (Lumbreras 1999: 258; Canziani 2009: 288, 1994). Podemos notar que el antecedente más próximo, relacionado a la orientación y a la construcción monumental, lo podemos encontrar en la costa central durante la época del Formativo Temprano, en los «templos en U» (Williams 1982).

La importancia del Sur en el caso de Pucllana está relacionada, también, a que en esta área de la pirámide se encuentra la parte más antigua, es decir las primeras construcciones fueron realizadas al Sur y de allí la pirámide crece en forma alargada hacia el Norte y luego las otras construcciones alrededor hacia el Este. La importancia del Sur puede ser considerada como punto central, en el cual podría ubicarse el Axis mundi (Eliade 1994:37).

Otro aspecto importante en la configuración espacial de la arquitectura es de las plataformas superpuestas, las que se observan al interior de los patios con la edificación de banquetas y el sistema de acceso, empleándose escalinatas adosadas y empotradas. También puede ser notado al exterior, cuando se unen dos patios y tratan de formar una unidad con niveles diferenciados. Y lo más importante es que dicho aspecto también se encuentra en la pirámide, notándose para la última etapa tres niveles muy marcados. Todos estos elementos manifestados en la arquitectura enfatizan la figura escalonada, la que podría considerarse como el imago mundi, de esta sociedad. La importancia de la arquitectura escalonada fue anteriormente sugerida y se ha tratado de relacionar a una tradición costeña (Vásquez 1984); el mismo empleo de los escalones en el área andina han sido consideradas como símbolos de importancia religiosa (Campana 2004).

\section{Forma, uso y función}

Estos patios presentan variedad de formas y en pocos casos son similares; varían por su tamaño; disposición, forma y ubicación de banquetas. Contrastan con los patios que tienen la misma disposición pero carecen de banquetas, estos pueden ser anteriores o posteriores a un patio con estructura escalonada.

18 De acuerdo a la imagen satelital de Google Earth. 
La forma responde a su localización dentro del asentamiento, los más amplios están en el Complejo Noreste; mientras que en la pirámide el tamaño disminuye a medida que se asciende. Las banquetas compuestas se ubican en las áreas más tempranas. Una diferencia drástica está relacionada al empleo de la pintura amarilla usada para pintar los muros y la banqueta; la mayoría pintadas están en la pirámide, en la parte baja se encontró solo un patio con este tipo de tratamiento; este color tendría una connotación religiosa; el empleo de dicho color es reportado para pirámides de otros sitios como Maranga (Shady y Narváez 1999), Pachacamac (Franco 2005) y Makat Tampu (Cárdenas 1998: 152).

En los pisos de estos patios con estructura escalonada no se ha encontrado ninguna evidencia cultural; al parecer estos fueron limpiados antes de ser rellenados; lo que se encuentra son áreas con huellas de quema, probablemente relacionadas a algunas actividades rituales. Pero si podemos señalar que albergaron mucho público, pues existe desgaste y evidencia de refacción de los pisos; en varios casos se han encontrado que en el momento de elaborar los pisos de los patios se realizaron pequeños hoyos de hasta $20 \mathrm{~cm}$ de profundidad, empleándose con palos de $5 \mathrm{~cm}$ de diámetro.

Las banquetas igualmente se mantienen limpias, pero con desgate de uso. Por el momento, solamente podemos hacer algunos comentarios; en principio señalar que servían para la reunión de muchas personas. Sobre su probable uso podemos encontrar justificación en un pasaje de Ritos $y$ Tradiciones de Huarochiri; en que se menciona la existencia de una terraza en las cuales suelen sentarse los huéspedes en las asambleas; en ella ocurrió una actividad muy interesante. Huatiacuri, uno de los hijos de Pariacaca, en uno de las pruebas que libró con señores yungas, subió a una terraza con su esposa llevando su chicha, en ella estaban los retadores que también tenían chicha; primero bebió de todos los que estaban allí y luego le tocó repartir a él, como su cántaro era mágico (vertía chicha sin terminarse) alcanzó para todos los personajes, acomodados, probablemente en fila, ya que señala que repartió de canto a canto; emborrachó a todos y ganó de esta manera la prueba (Tylor 1999: 63-65). De allí podemos enfatizar la existencia de actividades paralelas que se realiza en la banqueta y en la parte baja, ambas casi con una cierta autonomía; sin que directamente los que ocupan la parte baja sean solamente espectadores; sino que dentro del espacio general se hagan actividades y que cada participante sabe el lugar que le corresponde; de allí que no estemos de acuerdo en considerar a estas banquetas como altares, en la forma como se conceptualiza en occidente; sino que todo el patio en considerado sagrado, pero dentro de él unos más que otros; donde el lenguaje principal es el de la distinción entre los que están arriba y los que están abajo.

Hemos tratado de buscar una conceptualización para tener más referentes respecto al uso de banquetas; encontrando los términos quechuas de tiana y pata, ambos señalan como escaño o poyo para asentarse (Santo Thomas 2006); si bien en el caso inca si existe un espacio en el cual se sienta el Inca; en la sociedad Lima, hasta el momento no hemos encontrado un elemento que marque esta diferenciación y más bien se tienen banquetas, que nos dan la idea que puede ser ocupado por un grupo. Saber la diferenciación que pueda estar marcando esta jerarquización es tema de otra investigación; pero al menos este tipo de manejo de la sociedad puede ser muy importante para realizar los trabajos corporativos, cuyo producto son los inmensas obras públicas.

\section{Variación temporal y las implicaciones sociales}

Los patios con estructuras escalonadas de Pucllana, nos permiten tener una visión temporal; ya que los patios corresponden a cuatro etapas constructivas superpuestas, y cronológicamente diferenciables $^{19}$. Los de la fase I (corresponde a 3 patios), tienen fechado que fluctúan entre el año 530 hasta el año 570 d.c, aunque este podría retroceder hasta el año 470 d.C; que encajaría dentro de la época

19 Se ha tratado de buscar una media, cruzando la información de 7 fechados radiocarbónicos que se tienen directa e indirectamente relacionado a los patios de diferentes épocas; para de esta manera poder definir una secuencia desde lo más temprano a lo más tardío. 
temprana de Lima Medio. Los de la fase II (4 patios), estarían construyéndose entre el año 545 y 585 d.C.; estos se ubicarían dentro de la etapa tardía de Lima Medio. Los de la fase constructiva III (21 patios), estarían siendo construidos entre el año 555 y 600 d.C.; estos se ubicarían dentro de la etapa Lima Tardío. Finalmente tenemos dos patios que corresponden a construcciones antes del abandono; los mismos que no se cuentan con asociaciones de fechados absolutos; pero que debe ser posteriores al año 600, pero anteriores al año 650 d. $C^{20}$.

En la época de Lima Medio solo existe la pirámide, que tiene un área reducida y una altura de 15 $\mathrm{m}$, las diferencias se dan por el material constructivo (tapia primero, adobes cúbicos y paralelepípedos cuadrangulares luego. En Lima Tardío el volumen de la pirámide crece en forma longitudinal al NE y en altura alcanza los $22 \mathrm{~m}$, además se construye el complejo Noreste en la parte baja, del cual no conocemos su tamaño real; allí se emplea el adobe paralelepípedo alargado.

Sobre los patios escalonados, los de Lima Medio tienen banquetas que se disponen en uno de sus lados, en las épocas más tempranas se ubican al Sur y en las más tardías al Sur y otros al Oeste; en estos últimos las banquetas pueden tener hasta dos niveles y en un caso se complementa con otros accesorios a modo de decoraciones; todas presentan pintura amarilla y existe mucha superposición, respetando las dimensiones del patio; además un rasgo arquitectónico que podría ser indicador temporal es el uso de escalinatas empotradas con forma de media luna ubicada en la sección media de la banqueta.

En Lima Tardío, existe una variedad de patios, notándose una diferencia entre los que se ubican en la pirámide con los que están en el Complejo Noreste, por el empleo del color amarillo y por las dimensiones, siendo las más amplias las que están en el complejo Noreste; en lo que respecta a la ubicación de sus banquetas estás pueden tener una sola, ubicadas al Sur y una al Este; cuando están en dos de los lados pueden estar al Sur y al Oeste, al Este y Oeste, al Sur y al Norte; y también se reporta un patio con banquetas en tres de sus lados, ubicada en el Complejo Noreste.

Los dos patios construidos casi en el momento del abandono, tienen banquetas al Sur y al Oeste; no presentan ninguna pintura, son angostas y con mayor altura; además para acceder tienen una escalinata adosada.

\section{Conclusiones}

Los patios con estructuras escalonadas son, hasta este momento, los espacios arquitectónicos de mayor jerarquía registrados en Pucllana y los que ocupan la mayor proporción de espacio en el sitio. Este comportamiento puede extenderse a otros sitios contemporáneos de la Cultura Lima.

Dentro de Pucllana existe un sistema de circulación en sentido Norte-Sur y Este-Oeste; las áreas aumentan de jerarquía de Sur a Norte, hallándose al Sur las partes más altas de la Pirámide. Los pasadizos que unen cada nivel de patios tienen orientación de Este a Oeste; todo esto forma parte de rituales de tránsito que aún no entendemos del todo.

Existe la intención de plasmar en la arquitectura figuras escalonadas; reflejadas al interior de los patios, mediante banquetas; exteriormente por el desnivel de patios continuos y por el diseño propio de la estructura piramidal.

El uso de cada patio debió estar destinado a actividades con la participación de público; pero pertenecientes a diferente grupos. Estas diferencias pueden notarse dentro de cada ambiente, en los que las banquetas son destinadas a un grupo que tiene un mayor estatus que el otro.

Cronológicamente estos patios, a inicios de Lima Medio son pequeños; luego la complejidad aumenta con el uso de banquetas compuestas en la parte más tardía de Lima Medio; para, finalmente alcanzar su apogeo y, con ello, mayor variedad en Lima Tardío. Se observa al final de dicha época,

20 Esto de acuerdo a los fragmentos de cerámica de construcciones contemporáneas. 
casi en el proceso de abandono, un cambio, se abandona el uso del color amarillo como pintura y las banquetas son más delgadas y elevadas.

\section{Agradecimientos}

Agradecemos a las instituciones que hacen posible la continuidad del proyecto durante más de 31 años: al Ministerio de Cultura y la Municipalidad de Miraflores; así mismo a todo el personal del Proyecto de Investigación, Conservación y Puesta en Valor de Huaca Pucllana; para este artículo en especial a Miguel Quesada por el plano y José Chate por las fotografías.

\section{BibliografíA}

\section{ALARCÓN, Pedro}

1971 Tres fases Constructivas de la Huaca San Marcos. Tesis para optar el grado de Bachiller en Arqueología. Lima: Universidad Nacional Mayor de San Marcos.

CAMPANA, Delgado

2004 «El Triángulo escalonado, el poder y la arquitectura en el antiguo Perú». Arkinka 9 (8): 86-93. Revista de arquitectura, diseño y construcción. Lima.

CANZIANI, José

1996 «Arquitectura Paracas». Arkinka 1 (6): 79-94. Revista de arquitectura, diseño y construcción. Lima.

2009 Ciudad y territorio en los Andes. Contribuciones a la historia del urbanismo prehispánico. Lima: Pontificia Universidad Católica del Perú.

CÁRDENAS, Mercedes

1998 «Cultura Lima: el adobe como material de construcción». Boletín del Instituto Riva-Agüero 189: 131186. Lima: Pontifica Universidad Católica del Perú, Instituto Riva-Agüero.

DILLEHAY, Tom

2008 «Pequeñas y grandes 'voces' en los foros públicos del discurso andino». En: Peter Kaulicke y Tom Dillehay (editores), Boletín de Arqueología PUCP 9 (2005): 25-43. Lima: Pontificia Universidad Católica del Perú.

ELIADE, Mircea

1994 Lo sagrado y lo profano. Colombia: Editorial Labor S.A. (Novena Edición).

FLORES, Isabel

1981 «Investigaciones arqueológicas en la Huaca Juliana, Miraflores-Lima». Boletín de Lima 13: 65-70. Lima: Editorial Los Pinos.

2005 Pucllana: esplendor de la Cultura Lima. Lima: Instituto Nacional de Cultura.

FLORES, I., H. CHUCHÓN, J. CCENCHO y P. VARGAS

2012 La doble tela de los muertos. Tejidos especiales Wari de Pucllana. Lima: Proyecto de Investigación, Conservación y Puesta en Valor de Huaca Pucllana-Auqi Ediciones.

FRANCO, Régulo

1998 «Cajamarquilla. La Arquitectura de un Gran Centro Prehispánico de la Costa Central». Arkinka 3 (36): 72-89. Revista de arquitectura, diseño y construcción. Lima.

FRANCO, Régulo y Ponciano PAREDES

2000 «El Templo Viejo de Pachacamac: Nuevos aportes al estudio del Horizonte Medio». En Boletín de Arqueología PUCP 4: 607-630. Lima: Pontificia Universidad Católica del Perú.

2005 «El templo Viejo de Pachacamac. Nuevas Investigaciones». Arkinka 10 (117): 78-86, Revista de arquitectura, diseño y construcción, Lima.

GUERRERO, Daniel

1998 «Prehistoria». En: Luis Enrique Tord (editor), Historia del distrito de La Molina: 65-107. Lima: Municipalidad de la Molina. 
JIJÓN Y CAAMAÑO, Jacinto

1949 Maranga, contribución al conocimiento de los aborígenes del Valle del Rímac, Perú. Quito: La Prensa Católica.

KROEBER, Alfred Louis

1954 Proto Lima: A Middle Period Culture of Peru. Fieldiana Anthropology 44(1). Chicago: Chicago Natural History Museum.

LUMBRERAS, Luis

1999 «Formación de las sociedades urbanas». Historia de América Andina (las Sociedades aborígenes) Volumen 1: 224-281. Quito.

MOORE, Jerry

1996 Architecture and power in the Ancient Andes. The archaeology of public buildings. Cambridge: Cambridge University Press.

PATTERSON, Thomas

1966 Pattern and Process in the Early Intermediate Period of The Central Coast of Peru. Anthropology 3. University of California - Berkeley and Los Angeles.

RAVINES, Róger

1994 «Las culturas preincas». Arqueología del Peru (Tomo II). Lima: Editorial Brasa S.A.

Ríos, Niltón

2008 Restos de Actividades Rituales en la Segunda Etapa Constructiva de una Plaza Lima Tardio: Un Caso en Pucllana. Tesis para optar el Título Profesional de Licenciado en Arqueología. Lima: Universidad Nacional Mayor de San Marcos.

RÍOS, Niltón y José CCENCHO

2009 «Cambios en la sociedad Lima reflejados en la arquitectura del centro Ceremonial de Pucllana durante las primeras épocas del Horizonte Medio: Las evidencias de la Plataforma IV». Arqueología y Sociedad 20: 91-118. Lima: Museo de Arqueología y Antropología, Universidad Nacional Mayor de San Marcos.

SANTO THOMAS, Fray Domingo

2006 [1566] Lexicon Quechua. Editado por Jan Szmiñiski. Convento de Santo Domingo-Qorikancha; Sociedad Polaca de Estudios Latinoamericanos; The Hebrew University of Jerusalem. Lima.

SHADY, Ruth y Joaquín NARVAEZ

1996 Historia Prehispánica de Lima: Arqueología de la Huaca San Marcos. Lima: Museo de Arqueología y Antropología de la Universidad Nacional Mayor de San Marcos.

STUMER, Louis

1954 «Antiguos Centros de Población en el Valle del Rímac». Revista del Museo Nacional. Tomo XXIII: 212 - 241. Lima.

TELLO, Julio

1999 Arqueología del Valle de Lima. Cuadernos de Investigación del Archivo Tello 1. Museo de Arqueología y Antropología Universidad Nacional Mayor de San Marcos, Lima.

TYLOR, Gerald

1999 Ritos y tradiciones de Huarochiri. Lima: Instituto Francés de Estudios Andinos, Banco Central de Reserva del Perú, Universidad Particular Ricardo Palma.

VALLADOLID, Clide

1991 «Huallamarca». Pachacamac, Volumen 1, N¹: 133-134. Revista del Museo de la Nación. Lima.

VÁSQUEZ, Segundo

1984 «La Waka Pucllana, Lima». Gaceta Arqueológica Andina N 9: 8-9. Instituto Andino de Estudios Arqueológicos. Lima. 